Cfr-working paper No. 07-12

Time and the price Impact of a trade:

A structural approach

J. Grammig • $\bullet$. Theissen $\bullet 0$.

centre for financial Research Look deeper 


\title{
Time and the Price Impact of a Trade:
}

\section{A Structural Approach}

\author{
Joachim Grammig \\ Erik Theissen \\ Oliver Wuensche
}

July 16, 2007

\begin{abstract}
Dufour and Engle (2000) have shown that the duration between subsequent trade events carries informational content with respect to the evolution of the fundamental asset value. Their analysis supports the notion that "no trade means no information" derived from Easley and O'Hara's (1992) microstructure model. This paper revisits the role of time in measuring the price impact of trades using a structural model and provides challenging new evidence. For that purpose we extend Madhavan et al.'s (1997) model to account for time varying trading intensities. Our results confirm predictions from strategic trading models put forth by Parlour (1998) and Foucault (1999) in which short durations between trades are not related to the processing of private information. Instead, they are caused by strategic trading of impatient non-informed agents who use market orders more intensively when order book liquidity is high.

Keywords: Price impact, microstructure, trading intensity, duration, strategic trading models JEL classification: G10, C32
\end{abstract}

Contact details authors. Email: joachim.grammig@uni-tuebingen.de, theissen@uni-bonn.de, oliver.wuensche@uni-tuebingen.de postal address: Joachim Grammig and Oliver Wuensche: Faculty of Economics, University of Tuebingen, Mohlstr. 36, 72074 Tuebingen, Germany, phone: +49 70712076009 , fax: +49 707129 5546. Erik Theissen: Faculty of Economics, University of Bonn, Adenauerallee 24-42, 53113 Bonn, Germany, phone: $+49+228+739208$, fax: $+49+228+735924$. Joachim Grammig and Erik Theissen are research fellows at the Centre for Financial Research (CFR), Cologne. We thank Ekkehart Boehmer, Alfonso Dufour, Stefan Frey and participants at ESF workshop on High Frequency Econometrics (U of Warwick) and the 2006 Conference on the Microstructure of Financial Markets in Europe (U of Konstanz) for helpful comments. We thank the German Stock Exchange for data sponsorship, and, in particular, Uwe Scheickert and Miroslav Budomir who shared their market expertise with us. We further thank the German Research Foundation (DFG) and the CFR for financial support. We are responsible for any remaining errors. 


\section{Introduction}

Why do security prices change? What is the amount of price-relevant information contained in a trade event? And in which way is the phenomenon that the time intervals between trade events exhibit idiosyncratic patterns associated with information processing? The availability of financial markets transaction level data allows to address those questions. Valid answers are interesting for both academia and decision making of investors and designers of trading venues. It is thus not surprising that a vast literature has evolved, theoretical and empirical, in which these questions are addressed. Bringing together the empirical microstructure literature originating in the seminal papers by Hasbrouck (1991a,b) who introduced vector autoregressive models (VARs) in microstructure, and recent contributions to modeling the properties of financial duration processes (Engle and Russell (1998), Engle (2000)), Dufour and Engle (2000) investigate the role of time varying transaction intensities in measuring the informational content of trades. Their paper made a strong point for the "no trade means no information" prediction derived from Easley and O'Hara's (1992) microstructure model.

This paper revisits the role of time in measuring the price impact of trades using a structural framework and provides challenging new evidence. Instead of employing an agnostic VAR, we extend Madhavan et al.'s (1997) seminal model (MRR) to account for time varying trading intensities. To model the duration process we combine the MRR model and Engle and Russell's (1999) ACD framework. We estimate both the Dufour/Engle VAR and the extended MRR model for a cross section of stocks traded on one of the largest Continental European Markets and also, for robustness checks, on NYSE data. The results challenge the "no trade means no information" interpretation. Rather, our analysis corroborates predictions from strategic trading models put forth by Parlour (1998) and Foucault (1999), in which short durations between trades are not related to the processing of private information.

This paper connects to various streams in the literature which investigate the role of time in the trading process. The empirical analysis provides an empirical test of the predictions of theoretical microstructure models involving the role of time in the trading process. Due to their different inherent assumptions, these models deliver conflicting predictions. For instance, Diamond and Verrecchia (1987) predict that in the case of short sale constraints long intervals of trade inactivity are evidence for bad news. On the other hand, in absence of such restraints, the model put forth by Easley and O'Hara (1992) implies that long no-trade 
intervals indicate that there is no new information. In their model, informed traders split up their orders in smaller chunks in order to disguise their trading motive. The order splitting strategy increases trading intensity, and leads to shorter durations between trades which then tend to be more informative w.r.t. the evolution of the asset price. Another classic reference is Admati/Pfleiderer (1988). In their model, non-informed liquidity traders cluster during periods of the trading day. This implies that high trading intensity would be associated with less informed trading. Although traders with private information may hide in the crowd of liquidity traders, the price impact of their trades is "cushioned" by the trading of the uninformed liquidity traders. Recent strategic trading models (Parlour (1998) and Foucault (1999)) provide more elaborate explanations for such a clustering process. In Parlour's (1998) model, large depth on the bid side increases buyer "aggressiveness", in other words: more buy market orders, more (buyer initiated) trading activity. The reasoning is symmetric for the sell side. Arguably, periods of high liquidity (measured as the depth at the best quotes) in limit order markets are associated with a lesser degree of private or public information in the market. Specifically, patient limit order traders, who are not trading for reasons of exploiting their superior information, and who are not afraid of being "picked off" by an informed order or adverse price movement, will supply ample liquidity. Thus, high liquidity in the order book emerges during non-informative periods. As liquidity traders gather together (via limit order submission, they supply liquidity) during non-informative periods, trading becomes more aggressive (more market orders triggering trades) when impatient traders strive to get priority over standing limit orders.

The second stream in the literature to which this paper connects to is the statistical modeling of time varying transaction intensities in financial markets. Engle and Russell's (1998) seminal contribution triggered a growing literature that proposes statistical methodologies to account for the idiosyncratic time series properties of financial duration processes (e.g. Engle (2000), Zhang, Russell, and Tsay (2001) Bauwens and Giot (2001), Fernandes and Grammig (2006)). Dufour and Engle (2000) linked this literature to a classical empirical microstructure methodology introduced by Hasbrouck (1991a, 1991b) who proposed to measure price impacts of trades via a VAR framework. Hasbrouck's VARs approach does not explicitly take into account the fact that the time between trades and quote updates is varying. The potential information contained in these no-trade intervals is neglected. Dufour and Engle (2000) showed 
that accounting for the time between trades does matter in measuring trade informativeness in a Hasbrouck-VAR framework. Dufour and Engle (2000) estimate their model on a cross section of stocks using the 1991 TORQ data base. Their study made a strong case for the "no trade means no information" prediction derived from Easley and O'Hara (1992). They found that trades after short durations have a significantly higher price impact than trades after long durations.

The third stream in the literature with which our contribution is connected, is the class of structural models introduced by Glosten and Harris (1988), Madhavan, Richardson, and Roomans (1997) and Huang and Stoll (1997). In contrast to Hasbrouck's VAR framework, these models contain structural equations for the evolution of the latent asset price which depends on the informational content of trade events. Furthermore, the anticipatory behavior of liquidity suppliers who take into account price impacts of trades (due to informed trading), order processing costs, and possible costs of holding unwanted inventory, is explicitly accounted for. As in Hasbrouck's VAR methodology, however, the information allegedly contained in no-trade intervals is not taken into account.

This paper contributes to the literature in the following way. We extend the Madhavan et al. (1997) (MRR) model to account for time-varying trade intensities, and revisit the role of time in measuring the informational content of a trade. To account for time varying trade intensities in a structural model we combine the MRR model with the autoregressive conditional duration (ACD) model introduced by Engle and Russell (1998). To our knowledge this paper is the first to provide a link of the structural models of market microstructure to the literature that deals with the modeling of dynamic duration processes. We show how structural parameters and the parameters of the ACD can be conveniently and simultaneously estimated using the Generalized Method of Moments (GMM). We estimate both the Dufour/Engle VAR and our extended MRR model on a cross section of stocks traded on one of the large European Stock markets, the Frankfurt Stock Exchange (FSE) which is operated as an automated auction market. For a robustness check the model is also estimated on a matched sample of NYSE traded stocks. One advantage of using the FSE data is their excellent quality. Problems that arise from misclassified trades, which can have severe consequences (see Boehmer, Grammig, and Theissen (2006)), are avoided. Furthermore, as open order book markets become increasingly important, it seems interesting to estimate these 
models using recent data generated within these market structures.

The main results are as follows. Estimating the extended MRR model on European and NYSE data we find that trades occurring after periods of inactivity (long durations between trades) are more informative than trades during active periods (short durations) a result that is also confirmed for the NYSE control sample. The adverse selection component of the spread is higher for trades after long durations. We also find that adverse selection costs of less actively traded stocks are more severely affected by the time between transactions than more actively traded stocks. These results challenge the "no trade means no information" result of Dufour and Engle (2000). Rather than supporting the predictions of the Easley and O'Hara (1992) model, our findings are more in accord with the models of strategic trading in limit order markets (Parlour (1998), Foucault (1999)). As noted above, a high trading intensity in those models is caused by the submission of market orders by impatient, yet uninformed traders who strive aggressively for priority for their orders when the liquidity on their own market side is high (small spread, large depth). However, liquidity supply is ample when limit order traders are not afraid of being picked off by an adverse price movement (be it induced by public or private information processing). These results emphasize the relevance of the Admati/Pfleiderer (1988) explanation that through clustering of liquidity-induced trading, short durations between trades are associated with smaller price impact of trades.

Estimating Dufour and Engle's extended Hasbrouck-VAR on our data we broadly confirm their main conclusions. The contradictory results must therefore be attributable to the methodology used to measure the informational content of trade. Investigating this issue in greater detail we conjecture that the differences are caused by the way the econometric methodologies deal with market-to-limit orders which are a quite popular instrument used by traders.

The remainder of the paper is organized as follows. Section 2 describes the data used for the analysis and the market structure. The empirical methodology employed in our study is presented in section 3. In section 4 we discuss the empirical results and section 6 concludes.

\section{Market Structure and Data}

In our empirical analysis we use data from the automated auction system Xetra which operates at various European trading venues, like the Vienna Stock Exchange, the Irish Stock 
Exchange, the Frankfurt Stock Exchange (FSE) and the European Energy Exchange. ${ }^{1}$ Specifically, our data are the 30 DAX stocks traded at the FSE in the first quarter, 2004. We also use TAQ data for a matched sample of NYSE traded stocks as a robustness check. Since the NYSE trading process has been outlined in many papers and textbooks (see e.g. Bauwens and Giot (2001) and Harris (2003) for lucid surveys) we refrain from adding another description. The Xetra trading system, however, warrants some explanations.

Xetra is a pure open order book system developed and maintained by the German Stock Exchange. It has operated since 1997 as the main trading platform for German blue chip stocks at the FSE. Since the Xetra/FSE trading protocol is the data generating process for this study we will briefly describe its important features. ${ }^{2}$

Between an opening and a closing call auction - and interrupted by another mid-day call auction - Xetra/FSE trading is based on a continuous double auction mechanism with automatic matching of orders based on the usual rules of price and time priority. During preand post-trading hours it is possible to enter, revise and cancel orders, but order executions are not conducted, even if possible. During the year 2004, the Xetra/FSE hours extended from 9 a.m. C.E.T to 5.30 p.m. C.E.T. For blue chip stocks there are no dedicated market makers like the Specialists at the New York Stock Exchange or the Tokyo Stock Exchange's Saitori. For some small capitalized stocks listed in Xetra there may exist so-called Designated Sponsors - typically large banks - who are required to provide a minimum liquidity level by simultaneously submitting competitive buy and sell limit orders.

In addition to the traditional limit and market orders, traders can submit so-called iceberg (or hidden) orders. An iceberg order is similar to a limit order in that it has pre-specified limit price and volume. The difference is that a portion of the volume is kept hidden from the other traders and is not visible in the open book.

Xetra/FSE faces some local, regional and international competition for order flow. The FSE maintains a parallel floor trading system, which bears some similarities with the NYSE, and, like in the US, some regional exchanges participate in the hunt for liquidity. Furthermore, eleven out of the thirty stocks we analyze in our empirical study are also cross listed at the

\footnotetext{
${ }^{1}$ The Xetra technology was recently licensed to the Shanghai Stock Exchange, China's largest stock exchange.

${ }^{2}$ The Xetra trading system resembles in many features other important limit order book markets around the world like Euronext, the joint trading platform of the Amsterdam, Brussels, Lisbon and Paris stock exchanges, the Hong Kong stock exchange described in Ahn et al. (2001), and the Australian stock exchange, described in Cao et al. (2004).
} 
NYSE, as an ADR or, in the case of DaimlerChrysler, as a globally registered share. However, the electronic trading platform clearly dominates the regional and international competitors in terms of market shares, at least for the blue chip stocks that we study in the present paper.

The Frankfurt Stock Exchange granted access to a database containing complete information about Xetra open order book events (entries, cancelations, revisions, expirations, partial-fills and full-fills of market, limit and iceberg orders) which occurred during the first three months of 2004 (January, 2nd - March, 31st). The sample comprises the thirty German blue chip stocks constituting the DAX30 index. Based on the event histories we perform a real time reconstruction of the sequences of best bid and ask prices and associated depths, and record a time stamped series of transactions (with transaction price and volume) initiated by market order or marketable limit order traders. The resulting data are comparable to the Trade and Quote (TAQ) data supplied by the New York Stock Exchange. Contrary to the TAQ data set, we know the correct trade direction identifier and do not have to apply trade classification algorithms, e.g. Lee and Ready (1991).

insert table 1 about here

Table 1 reports descriptive statistics for the thirty stocks that constitute the DAX30 index. The table also displays the sorting of the thirty stocks into four groups. The stocks are grouped according to their trading frequency (measured as the average number of trades per day). Group one contains the most frequently traded stocks, while group four the least frequently traded stocks. The table contains the market capitalization, the daily turnover and the average daily number of trades as well as the average midquote price, the quoted spread and the average relative quoted spread.

\section{Empirical Methodology}

\subsection{The Dufour/Engle Approach}

Before introducing the structural framework that we use to investigate the role of time and the price impact of trades let us briefly review Dufour and Engle's (2000) extension of Hasbrouck's (1991a,b) bivariate vector autoregressive model. To measure the price impact of trades and the role of duration between trade events, Dufour and Engle set up a VAR that contains two 
equations, one that accounts for the dynamics of the midquote revision process and one that models the evolution of the direction of trades:

$$
\begin{aligned}
R_{i} & =\sum_{j=1}^{5} a_{j} R_{i-j}+\gamma_{o p e n} D_{i} Q_{i}+\sum_{j=0}^{5} b_{j} Q_{i-j}+v_{1, i} \\
Q_{i} & =\sum_{j=1}^{5} c_{j} R_{i-j}+\gamma_{\text {open }} D_{i-1} Q_{i-1}+\sum_{j=1}^{5} d_{j} Q_{i-j}+v_{2, i} \\
\text { where } \quad & b_{j}=\gamma_{j}+\delta_{j} \ln \left(T_{i-j}\right) .
\end{aligned}
$$

$Q_{i}$ is an indicator of the side of the trade taking the value 1 for a buyer initiated trade and -1 for a seller initiated trade. The counter-party of the trade is the liquidity supplier, either a dedicated market maker or the open limit order book. $R_{i}$ denotes the instantaneous midquote revision after a trade. $T_{i}$ measures the time interval (in seconds) between the $i^{\text {th }}$ and the $i-1^{\text {th }}$ trade. Note that the $i^{\text {th }}$ trade in time affects the midquote revision contemporaneously while $Q_{i}$ is only affected by lagged midquote revisions. The model ticks in event time. A new trade increases $i$ by one. The extension of Dufour and Engle (2000) to the Hasbrouck (1991a,b) model is the parameterization of the price impact $b_{j}$ as a function of time between trades (duration) $T_{i}$.

The parameter $b_{0}$ is a raw measure of the informational content of the trade. The higher $b_{0}$, the larger the instantaneous price impact of a trade. Whether a longer duration between trades $T_{i}$ leads to an increasing or decreasing price impact depends on the parameter $\delta_{0}$. If $\delta_{0}$ is negative a longer trade duration would be associated with a reduced price impact and hence, a less informative trade. In other words, a low trading frequency would be related to less informative trades if $\delta_{0}$ is negative. Estimation of the model can be straightforwardly conducted via equation by equation OLS. The role of the price impact of trades can be assessed by the size of the parameter estimates of $\delta_{j}$ and, more sophisticated, by an impulse response analysis which, requires simulating future trade durations (see Dufour and Engle (2000) for details).

\subsection{A Structural Approach}

As an alternative to measuring the role of time in measuring the price impact of trades we resort to an alternative class of structural models which are extensively used in market 
microstructure. The most popular examples are the models proposed by Glosten and Harris (1988), Madhavan et al (1997) and Huang and Stoll (1997). These models consist of structural equations for the evolution of the fundamental asset value and the behavior of liquidity suppliers (market makers or limit order traders) which post bid and ask quotes anticipating the price impact of trades and demand compensation for involuntary inventory taking and order processing costs. One of the advantages of these models is the clear theoretical background that allows to give the parameter estimates a structural interpretation and allows for an economically meaningful decomposition of the spread. Let us briefly review the basic contents of the Madhavan et al (1997) model that we will extend below to account for a time varying trade intensity.

In the MRR model there are two factors driving the fundamental value of a stock. First, we have the public news factor. The second factor is private information which can be inferred from order flow and consists of the surprise in order flow multiplied with a measure for the degree of asymmetric information. For the post-trade expected value of a stock, $\mu_{i}$, results the following expression:

$$
\mu_{i}=\mu_{i-1}+\theta(\cdot) \cdot\left(Q_{i}-E\left[Q_{i} \mid Q_{i-1}\right]\right)+\varepsilon_{i}
$$

where $Q_{i}-E\left[Q_{i} \mid Q_{i-1}\right]$ measures the surprise in order flow and $\theta(\cdot)$ the degree of trade informativeness conveyed through a surprise in the order flow. $\varepsilon_{i}$ denotes the public news impact which is assumed to be an i.i.d random variable with zero mean and variance $\sigma_{\varepsilon}$. Liquidity providers know $\mu_{i-1}$ and $\varepsilon_{i}$ (public news accrued from $i-1$ to $i$ ) but not $Q_{i}$. But they can anticipate the effect of $Q_{i}$ and set bid and ask prices accordingly. Bid and ask prices are set to reflect the expected value of the stock plus a fixed component $\phi(\cdot)$ which can be interpreted as a compensation for order processing or possible inventory holding:

$$
\begin{aligned}
& \text { ask price: } P_{i}^{a}=\mu_{i-1}+\theta(\cdot)\left(1-E\left[Q_{i} \mid Q_{i-1}\right]\right)+\phi(\cdot)+\varepsilon_{i} \\
& \text { bid price: } P_{i}^{b}=\mu_{i-1}-\theta(\cdot)\left(1+E\left[Q_{i} \mid Q_{i-1}\right]\right)-\phi(\cdot)+\varepsilon_{i}
\end{aligned}
$$

Contrary to a market with a specialist where some transactions may be executed inside the spread, all buys (sells) with a smaller or equal volume than the best depth are executed 
at the prevailing best ask (bid) price. Trades inside the spread are not possible. It can easily be shown that $E\left[Q_{i} \mid Q_{i-1}\right]=\rho Q_{i-1}$ where $\rho$ is the first order autocorrelation of the trade indicator series. The equation for the transaction price can be expressed as

$$
P_{i}=\mu_{i}+\phi(\cdot) \cdot Q_{i}+\xi_{i}
$$

where $\xi_{i}$ is an i.i.d mean zero disturbance term which accounts for possible rounding errors due to price discretion. Combining (4) and (7) yields the following equation for transaction price changes

$$
\Delta P_{i}=\theta(\cdot)\left(Q_{i}-\rho Q_{i-1}\right)+\phi(\cdot)\left(Q_{i}-Q_{i-1}\right)+\varepsilon_{i}+\xi_{i}-\xi_{i-1} .
$$

We extend the basic MRR model in the following way. In the spirit of Dufour and Engle (2000), we specify the MRR model parameters $\phi(\cdot)$ and $\theta(\cdot)$ as a function of time and the duration between trades. Both parameters are assumed to depend on time of day dummies $d_{m, i}$ which accounts for the stylized fact that the spread has a pronounced deterministic time of day pattern. Following Dufour and Engle (2000) we also allow the log-duration between the last and the current trade to determine the parameter $\theta(\cdot)$ which measures the price impact of a trade. Specifically, we write

$$
\begin{aligned}
\phi\left(t_{i}\right) & =\gamma^{\phi}+\sum_{m=1}^{M} \lambda_{m}^{\phi} d_{m, i} \\
\theta\left(T_{i}, t_{i}\right) & =\gamma^{\theta}+\sum_{m=1}^{M} \lambda_{m}^{\theta} d_{m, i}+\delta \ln T_{i}
\end{aligned}
$$

where $t_{i}$ is the time of event $i$ and $T_{i}$ denotes the duration between the trade in $t_{i-1}$ and time $t_{i}$. As in Dufour and Engle (2000), we add one second to each duration before taking logarithms in order to avoid negative values. Incorporating a deterministic time of day pattern in the objective function directly instead of estimating the model separately for different periods of the day has the advantage that we can easily check for statistical significance of the estimated parameters $\lambda_{m}^{\phi}$ and $\lambda_{m}^{\theta}$. Since the price in $t-1$ is $P_{i-1}=\mu_{i-1}+\phi\left(t_{i-1}\right) Q_{i-1}+\xi_{i-1}$ equation 
(8) can now be written as:

$$
\Delta P_{i}=\theta\left(T_{i}, t_{i}\right)\left(Q_{i}-\rho Q_{i-1}\right)+\phi\left(t_{i}\right) Q_{i}-\phi\left(t_{i-1}\right) Q_{i-1}+\varepsilon_{i}+\xi_{i}-\xi_{i-1}
$$

Moment conditions can be derived as follows. Denoting $u_{i}=\varepsilon_{i}+\xi_{i}-\xi_{i-1}$, we can write

$$
\begin{aligned}
u_{i}= & \Delta P_{i}-\left[\left(\gamma^{\phi}+\sum_{m=1}^{M} \lambda_{m}^{\phi} d_{m, i}\right) Q_{i}-\left(\gamma^{\phi}+\sum_{m=1}^{M} \lambda_{m}^{\phi} d_{m, i-1}\right) Q_{i-1}\right. \\
& \left.+\left(\gamma^{\theta}+\sum_{m=1}^{M} \lambda_{m}^{\theta} d_{m, i}+\delta \ln T_{i}\right) \cdot\left(Q_{i}-\rho Q_{i-1}\right)\right]
\end{aligned}
$$

Together with a vector of time-of-day dummy variables $\mathbf{d}_{i}=\left(d_{1, i}, \cdots, d_{M, i}\right)^{\prime}$ and $\mathbf{z}_{i}=$ $\left(Q_{i}, Q_{i-1}\right)^{\prime}$, the resulting moment conditions are given by

$$
E\left[\begin{array}{c}
Q_{i} Q_{i-1}-\rho \\
u_{i} \\
u_{i} \mathbf{z}_{i} \\
u_{i} \mathbf{d}_{i} Q_{i} \\
u_{i} \mathbf{d}_{i-1} Q_{i-1} \\
u_{i} T_{i} \mathbf{z}_{i}
\end{array}\right]=0
$$

The first three moment conditions are the same as in the standard MRR model. The next two moment conditions result from the inclusion of the time-of-day dummies and the last one is due to the inclusion of the duration.

Madhavan, Richardson, and Roomans (1997) have argued that the surprise in order flow rather than order flow itself affects the fundamental value of an asset. If order flow is predictable, using raw order flow would imply that the fundamental value $\mu_{i}$ depends on information of time $t_{i-2}$. Otherwise the fundamental asset value is not a martingale any longer. Engle and Russell (1998) have shown that trade durations are also predictable. They have a strong time-of-day (diurnal) component, but beyond that even diurnally adjusted durations exhibit a strong serial correlation. It thus seems sensible to account for predictability of trade durations. Instead of modeling the evolution of the fundamental asset value as a function of raw trade durations we assume that duration shocks have an impact (via the trades) on the 
evolution of the asset value. This requires a decomposition of the trade duration sequence into a predictable and an unpredictable component. Following Engle and Russell (1998) we split up trade durations into three components, a diurnal time-of-day dependent component, a predictable component and a duration shock. Specifically, we have

$$
T_{i}=\Phi\left(t_{i}\right) \cdot \psi_{i} \cdot \nu_{i}
$$

where $\Phi\left(t_{i}\right)$ is the diurnal pattern of durations and $\psi_{i}$ evolves as

$$
\psi_{i}=\omega+\alpha \tilde{T}_{i-1}+\beta \psi_{i-1}
$$

where $\tilde{T}_{i}=T_{i} / \Phi\left(t_{i}\right) . \Phi\left(t_{i}\right) \psi_{i}$ is the conditional expected duration $E\left(T_{i} \mid \mathcal{F}_{i-1}\right)$ and $\nu_{i}$ is an i.i.d. duration shock with $E\left(\nu_{i}\right)=1$.

The alternative specification for the trade informativeness parameter $\theta(\cdot)$ is then written as:

$$
\theta\left(\tilde{\nu}_{i}, t_{i}\right)=\gamma^{\theta}+\sum_{m=1}^{M} \lambda_{m}^{\theta} d_{m, i}+\delta \ln \tilde{\nu}_{i}
$$

where $\tilde{\nu}_{i}=\tilde{T}_{i} / \psi_{i}+1$

Two step estimation of the ACD model parameters is feasible by first estimating the intra-day pattern $\Phi\left(t_{i}\right)$ with polynomial trigonometric regression (see Eubank and Speckman (1990)). The seasonally adjusted durations can then be computed as $\tilde{T}_{i}=T_{i} / \hat{\Phi}\left(t_{i}\right)$. In the second step, the parameters of the $\psi_{i}$ equation can be estimated by Maximum Likelihood. Joint estimation of ACD and structural parameters is also feasible. Grammig and Wellner (2002) show how estimation of ACD model parameters can be performed in a GMM framework. Drawing on their analysis, the moment conditions that estimate the extended MRR 
model parameters along with the ACD parameters are as follows:

$$
E\left[\begin{array}{c}
Q_{i} Q_{i-1}-\rho \\
u_{i} \\
u_{i} \mathbf{d}_{i} Q_{i} \\
u_{i} \mathbf{d}_{i-1} Q_{i-1} \\
u_{i} \mathbf{z}_{i} \\
u_{i} \tilde{\nu}_{i} \mathbf{z}_{i} \\
\nu_{i}-1 \\
\left(\nu_{i}-1\right)\left(\nu_{i-1}-1\right) \\
\vdots \\
\left(\nu_{i}-1\right)\left(\nu_{i-J}-1\right)
\end{array}\right]=0
$$

The first set of moment conditions are the same as in equation (13) except that $T_{i}$ is now substituted with $\tilde{\nu}_{i}$. The other moment conditions identify the ACD parameters. They make use of the assumption that $E\left(\nu_{i}\right)=1$ and that the covariance between $\nu_{i}$ and $\nu_{i-j}$ for all $j>i$ is assumed to be zero.

\section{Results}

Table 3 report the estimation results of the extended MRR model. We focus on the results obtained from the model in which the price impact of trades depend on duration shocks. The model in which raw durations are assumed to affect the price impact of trades delivers qualitatively the same results and supports the same conclusions (results are available upon request). To account for diurnal effects the time-of-day dummies in equations 10 and 16 are chosen to indicate the following six periods of the trading day: 9:00a.m - 9:30a.m; 9:30a.m 11:00a.m; 11:00a.m - 2:00p.m; 2:00p.m - 3:30p.m; 3:30p.m - 5:00p.m, 5:00p.m - 5:30p.m. When constructing the time-of-day dummies, the reference period is the midday period ranging from 11:00a.m - 2:00p.m..

insert table 3 about here

The estimation results confirm some well known stylized facts of financial market microstructure. The adverse selection component is significantly higher in the first half hour of 
the day, a result that is consistent with previous research studying the intra-day pattern of the spread. Furthermore, the order processing cost component is significantly higher at the end of the day for the vast majority of stocks. This indicates that liquidity providers demand a compensation for holding inventory overnight. The vast majority of the dummy variables for the remaining time periods are not significantly different from the mid-day reference period. The $\cup$-shaped pattern of the effective spread in Xetra is therefore due to higher adverse selection costs as well as higher order processing costs in the morning and higher order processing costs shortly before closing.

Let us now focus on what the results imply regarding an effect of a duration shock on trade informativeness. The results reported in table 3 show that the estimates of the key parameter $\delta$ are positive and significantly different from zero for all 30 stocks. This implies that longer no-trade intervals are associated with increasing information related costs of a trade. As such this results stands in sharp contrast with the results reported by Dufour and Engle (2000). We will discuss the reasons and provide explanations for the contradicting results in the next section. Let us first focus on assessing the economic importance of the results beyond statistical significance.

For the purpose of assessing the economic significance of our results, we split the adverse selection component $\theta\left(\tilde{\nu}_{i}, t_{i}\right)$ into a deterministic part

$$
\theta\left(t_{i}\right)=\gamma^{\theta}+\sum_{m=1}^{M} \lambda_{m}^{\theta} d_{m, i}
$$

and a part explained by the duration shock of the subsequent no-trade interval

$$
\theta\left(\tilde{\nu}_{i}\right)=\delta \ln \tilde{\nu}_{i}
$$

Both terms constitute the complete adverse selection component, $\theta\left(\tilde{\nu}_{i}, t_{i}\right)=\theta\left(t_{i}\right)+\theta\left(\tilde{\nu}_{i}\right)$. We can then compute for each stock the adverse selection share of the spread

$$
\operatorname{asr}\left(\tilde{\nu}_{i}, t_{i}\right)=\frac{\theta\left(\tilde{\nu}_{i}, t_{i}\right)}{\theta\left(\tilde{\nu}_{i}, t_{i}\right)+\phi\left(t_{i}\right)},
$$


the adverse selection share of the spread due to duration

$$
\operatorname{asr}\left(\tilde{\nu}_{i}\right)=\frac{\theta\left(\tilde{\nu}_{i}\right)}{\theta\left(\tilde{\nu}_{i}, t_{i}\right)+\phi\left(t_{i}\right)}
$$

and the share of adverse selection explained by duration to the total adverse selection component

$$
d a s r=\frac{\theta\left(\tilde{\nu}_{i}\right)}{\theta\left(\tilde{\nu}_{i}, t_{i}\right)} .
$$

Table 4 shows that the information related share of the implied effective spread is highest $(63.8 \%)$ for the least actively traded Xetra stocks. In contrast, the average adverse selection share of trade activity quartile 1 only amounts to $45.0 \% .^{3}$.

$$
\text { insert table } 4 \text { about here }
$$

Table 4 also shows that the effect of trade durations on trade informativeness is also stronger for less frequently traded stocks. We focus our attention on the indicator $\operatorname{asr}\left(\tilde{\nu}_{i}\right)$ which measures the importance of the duration component relative to the complete spread. The mean of the indicator $\operatorname{asr}\left(\tilde{\nu}_{i}\right)$ ranges from $13.4 \%$ for Xetra trade activity quartile 1 to $18.0 \%$ for Xetra trade activity quartile 4 . Averaged across stocks, the share of the duration component relative to the spread amounts to $14.2 \%$.

\section{insert figure 1 about here}

Figure 1 provides a graphical illustration of the intra-day pattern of the adverse selection component. As above, we eliminate the price level effect by dividing the spread components by the average mid-quote of the respective stock. While the deterministic pattern was estimated for six periods of the day, the duration component varies with every trade. To capture any possible systematic intra-day variation in the duration component, but not overload the figure, we compute ten minute means for the duration component. One can see that the standardized duration component does not vary substantially throughout the day but rather floats around a constant mean. In contrast, the deterministic portion resembles the well known L-shaped intra-day pattern of the adverse selection component. Adding up the two parts yields the complete adverse selection component.

\footnotetext{
${ }^{3}$ Note, that this number is strongly influenced by the stock DTE which has an $\operatorname{asr}\left(\tilde{\nu}_{i}, t_{i}\right)$ of $22.4 \%$ while all the other stocks in the quartile have an $\operatorname{asr}\left(\tilde{\nu}_{i}, t_{i}\right)$ of $46.3 \%$ and higher. However, compared to trade activity 4 , the information related component of the spread is substantially smaller.
} 
Table 5 reports further evidence for the negative relationship between the duration effect and trading frequency. The correlation coefficient is approximately -0.5 and significant. Moreover, the correlations of the estimated standardized spread components with their observed "counterparts", the relative quoted spread, the relative effective spread, the relative realized spread and the relative price impact as well as the market capitalization, and the trading frequency measured in daily number of trades have the expected signs and are significant. For example, the adverse selection component is positively correlated with the price impact while the correlation of the estimated order processing cost component is, if at all, only weakly related to the price impact. Another expected result is that order processing costs, mainly consisting of institutional fees, are not related to size or trading frequency of the stock. In contrast, adverse selection is strongly negatively correlated with both, size and trading frequency.

\section{insert figure 2 about here \\ insert figure 3 about here \\ insert figure 4 about here}

The importance of trading intensity for the information content of a trade is further illustrated in figures 2 and 3 . To produce these plots we have sorted all trade durations for groups of stocks into deciles. Decile 1 contains the smallest duration shocks while decile 10 contains the largest duration shocks. For each decile, we calculate the average standardized adverse selection component $\tilde{\theta}\left(T_{i}, t_{i}\right)$ and the average raw adverse selection component $\theta\left(T_{i}, t_{i}\right)$. The figures depict averages for each trade activity quartile. As can be seen in figure 3 , even in the quartile with the most actively traded stocks the adverse selection component doubles from trade intensity decile 1 to decile 10. A much stronger effect can be observed for the fourth quartile containing observations of the least actively traded stocks. Here, the adverse selection component more than triples when comparing the shortest trade durations in decile 1 with the longest trade durations in decile 10. In all four trade activity quartiles especially very large duration shocks have a large impact on the asset price. The slope of the line connecting the mean of decile 9 with the mean of decile 10 is steeper in every quartile. 
Note, that this result is not due to cross section or time-of-day variations of the trade durations. We have argued above that stocks traded less frequently tend to have higher adverse selection costs. To confirm that the upward sloping curve in figure 3 is not an artefact caused by intra-group variation of trading frequency in each trade activity quartile, we provide additional figures for a selected representative stock in each trade activity quartile in figure 4. We find for individual stocks the same relation between duration and adverse selection.

Note that the duration effect can also not be ascribed to co-movements in the intra-daily pattern of the trade duration and the adverse selection component. We have seen in figure 1 that the information induced part of the spread is high in the first half hour and lower for the rest of the day.

insert figure 5 about here

Figure 5 shows that trade durations rather have an inverted $\cup$-shaped intra-day pattern. At the beginning of the trading day, when adverse selection costs are high, trade durations tend to be short. Hence, we would rather expect a dampening of the positive duration effect through the intra-day variation. Therefore, we conclude that neither intra-group variation in the average trading frequency of the stocks nor the intra-day pattern in the deterministic part of the adverse selection component is responsible for the strong impact of trade durations.

insert figure 6 about here

As a robustness check we also estimate the model for a matched sample of NYSE traded stocks. The matching variable is the daily trading volume. The NYSE stocks included in the matched sample and their Xetra counterparts are reported in Table 6. Table 7 shows that the conclusions for the Xetra/DAX stocks also hold for the NYSE sample: The adverse selection parameter $\delta$ is positive and significant for 22 of the 30 stocks. The plots in figure 6 show the same upward sloping curve that suggests that the informational content of trades is higher after relatively long no-trade periods. However, from an economic point of view, the informational importance of trade durations for the spread seems smaller for the NYSE stocks compared to the Xetra/DAX stocks. 


\section{$5 \quad$ Interpretation and Discussion}

The statistical and economic significance of these results challenge the "no trade means no information" result of Dufour and Engle (2000) that is part of financial market microstructure's conventional wisdom. Rather than supporting the predictions of the Easley and O'Hara (1992) model, our findings are more in accord with the models of strategic trading in limit order markets (Parlour (1998), Foucault (1999)). Their contributions relate to a classic paper by Admati/Pfleiderer (1988). In the Admati/Pfleiderer model non-informed liquidity traders cluster during periods of the trading day which implies that high trading intensity would be associated with reduced trade informativeness. Traders with private information may hide in the crowd of liquidity traders, the price impact of their trades is "cushioned" by the trading of the uninformed liquidity traders. The models by Parlour (1998) and Foucault (1999) provide more elaborate explanations for such a clustering process. In Parlour's (1998) model, large depth on the bid side increases buyer "aggressiveness", in other words: more buy market orders, more (buyer initiated) trading activity. The reasoning is symmetric for the sell side. Arguably, periods of high liquidity (measured as the depth at the best quotes) in limit order markets are associated with a lesser degree of private information present in the market. Patient limit order traders, who are not trading for reasons of exploiting their superior information, and who are not afraid of being "picked off" by an informed order or adverse price movement, will then supply ample liquidity. Thus, high liquidity in the order book emerges during non-informative periods. As liquidity traders gather together (via limit order submission, they supply liquidity to the market) during non-informative periods, trading becomes more aggressive (more market orders triggering trades) when impatient (yet not superiorly informed) traders strive to get priority over standing limit orders.

As a matter of fact when estimating the Dufour/Engle model on our data, we find results that are, at least qualitatively, in line with their results (see table 2) in that short trade durations are associated with informed trading. Hence, the difference must be due to the empirical methodology, i.e. the way these models process the data and not the differences of trading processes in a pure limit order market and a hybrid market. In the following we will offer an explanation for the differences. A convenient way to implement a strategy that aggressively strives for price priority a'la Parlour (1998) are so-called market-to-limit orders. As a matter of fact, this order type is a very popular and frequently used instrument. A buy 


\begin{tabular}{|c|c|c|c|c|}
\hline & $t_{0}$ & $t_{1}$ & $t_{2}$ & $t_{3}$ \\
\hline & book state at $t_{0}$ & $\begin{array}{l}\text { book state after } \\
\text { small transaction } \\
(\mathrm{P}=105)\end{array}$ & $\begin{array}{l}\text { book state af- } \\
\text { ter market-to- } \\
\text { limit buy order } \\
\text { with limit price } \\
P=105 \text { that } \\
\text { takes best ask } \\
\text { and improves the } \\
\text { best bid }\end{array}$ & $\begin{array}{l}\text { state of book af- } \\
\text { ter best bid is } \\
\text { snatched }(P= \\
105)\end{array}$ \\
\hline \multirow{6}{*}{$M Q$} & 110 & 110 & & 110 \\
\hline & 105 & 105 & 110 & 110 \\
\hline & 102.5 & 102.5 & 107.5 & 105 \\
\hline & 100 & 100 & 105 & 100 \\
\hline & 90 & 90 & 100 & 90 \\
\hline & & & 90 & \\
\hline$\Delta M Q$ & & 0 & $4.9 \%$ & $-2.3 \%$ \\
\hline$\Delta P$ & & 0 & 0 & 0 \\
\hline
\end{tabular}

market-to-limit order consumes the volume at the best ask and the volume that exceeds the depth and the best ask is entered, at the limit price, on top of the queue of the limit orders standing on the bid side. As figure 7 shows, those trades that exactly consume the volume at the best quotes (which are in the vast majority of the cases market-to-limit-orders) indeed have significantly smaller duration than trades that consume only part of the depth at the best quote. Note that in a basic MRR model framework, a market-to-limit order would be deemed uninformative while in a Hasbrouck-VAR setting the events triggered by a marketto-limit order would be regarded as highly informative. The numerical example depicted in the following table makes that point clear: While the transaction price $(P)$ in the sequence of events does not change at all, the midquote changes $\triangle M Q$ is dramatic.

A market-to-limit order is a perfect tool for an impatient trader to gain price priority when own side liquidity is high. However, as the market-to-limit trader also immediately supplies liquidity (during times when liquidity is already high) it is hard to ascribe such a behavior to the exploitation of superior private information. It is rather the crowding-out effect in liquid markets described by Parlour (1998) and Foucault (1998) that we observe. In that perspective it seems more reasonable to view market-to-limit order trade events as a way to implement an aggressive trading strategy (without private information processing involved) than deem these trades as highly informative with respect to the fundamental asset 
value.

\section{Conclusion and Outlook}

This paper provides new evidence regarding the role of time in measuring the informational content of trades. Two novelties characterize our contribution. First, instead of the vector autoregressive methodology employed by Dufour and Engle (2000), we advocate the use of a structural model and extend Madhavan et al's (1997) model to account for a time varying trade intensities. For that purpose we employ Russell and Engle's (1998) ACD model. We estimate the model on a cross section of stocks traded in an automated open order book market, the Xetra system maintained by the German Stock Exchange. For robustness checks the models are also estimated on NYSE data. Xetra and the NYSE trading processes are quite different. In Xetra there are no dedicated market makers, trading is anonymous, and a fully computerized trading protocol matches liquidity supply and demand using an open limit order book trading platform. As a matter of fact, these are the characteristic features of all large Continental European stock markets. One of the advantages of using data from an automated auction system is the excellent data quality. Misclassification of trades that haunts empirical microstructure analysis is not an issue.

Dufour and Engle's (2000) paper made a strong case for the argument that trading intensity carries informational content with respect to the price impact of a trade. Specifically, their results provide evidence for the notion that "no trade means no information" one of the key predictions implied by Easley and O'Hara's (1992) microstructure model and arguably part of the conventional wisdom of financial market microstructure. The results reported in this paper provide quite contrasting evidence. As in the Dufour/Engle paper we also find that "time matters", both from a statistical and an economic point of view. However, our results imply that the informational content of a trade increases with the duration since the last trade. Our analysis suggests that in an automated order book market, but also in an hybrid framework like the NYSE, the role of time in measuring trade informativeness is more in accord with the predictions derived from the Admati/Pfleiderer (1988) model, and models of strategic trading in limit order markets (Parlour (1998), Foucault (1999)). In these models, high trading intensity is caused by the submission of market orders by impatient yet uninformed traders who strive aggressively for priority of their orders when the liquidity on 
their own market side is high (small spread, ample depth). Liquidity supply is high, however, when limit order traders are not afraid of being picked of by an adverse price movement (be it induced by public or private information processing). These results revive the relevance of the Admati/Pfleiderer (1988) model's prediction that through clustering of liquidity-induced trading, short durations between trades are associated with smaller trade informativeness. We outline that the reason why the different methodologies (extended Hasbrouck-VAR and extended MRR model) deliver contradicting results is mainly rooted in the way market-to-limit orders are treated in the two econometric frameworks.

Besides providing an additional note to answer the question "Why do securities prices change and what is the role of trading intensity in the process?" our results have interesting policy implications for the design of trading systems. One could argue for the need of circuit breakers during high trading intensities as processing of (private) information may harm uninformed market participants. However, our results indicate that circuit breaking via a call auction mechanism or additional liquidity supply by a dedicated market maker, say, would rather be advisable after long non-trading intervals. 


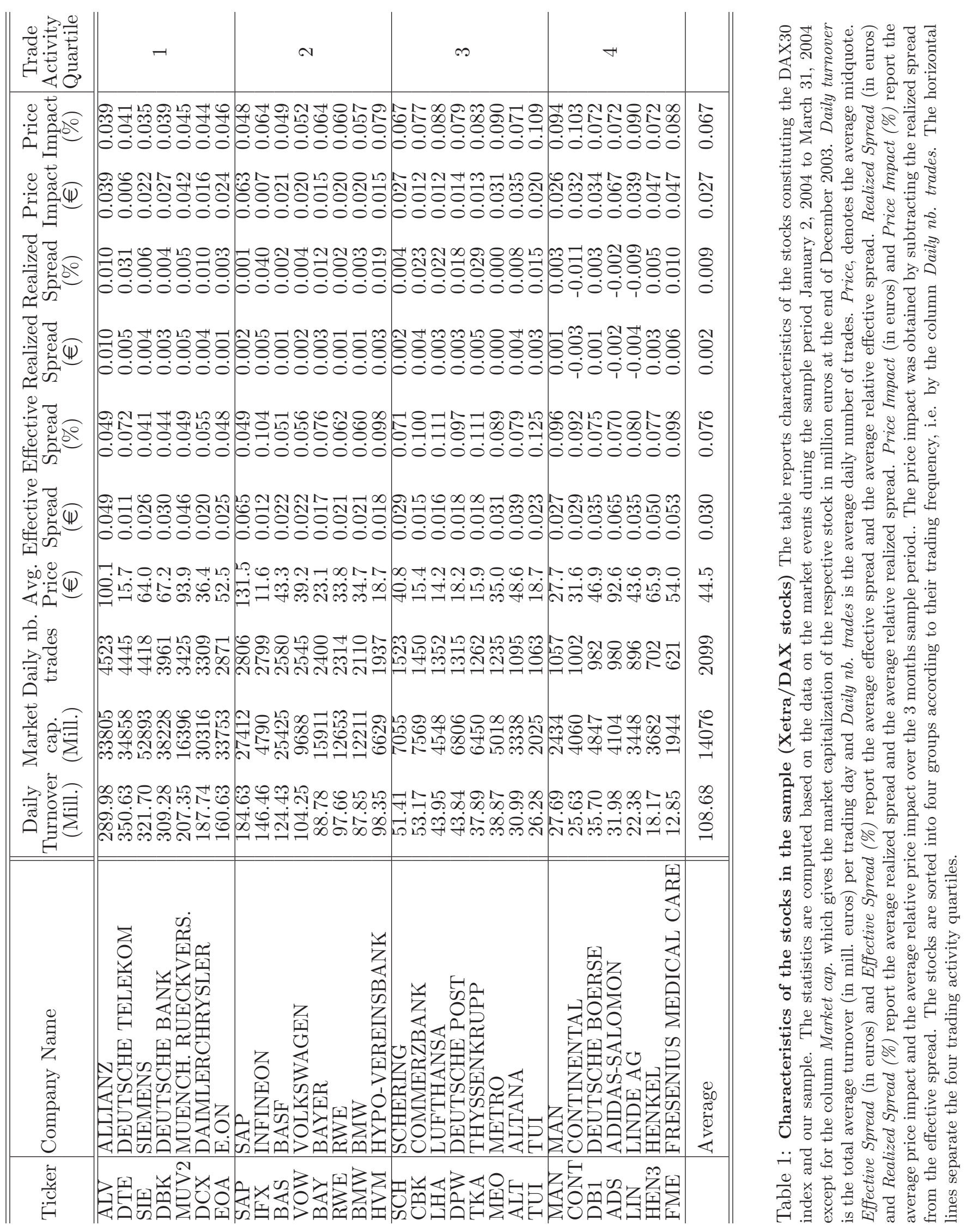




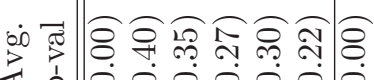
a ée ée é i

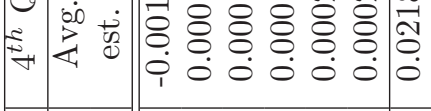

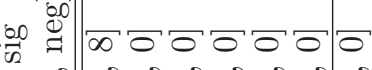
* \#

क के

i

$\mid$\begin{tabular}{llllll|l}
0 & 0 & 0 & 0 & 0 & 0 & \\
0 & 0 & 0 & 0 & 0 & 0 & 0 \\
0 & 0 & 0 & 0 & 0 & 0 \\
1 & 0 & 0 & 0 & 0 & 0 & 0 \\
0
\end{tabular}

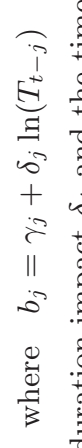

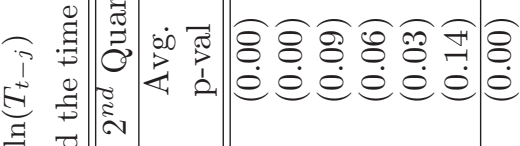

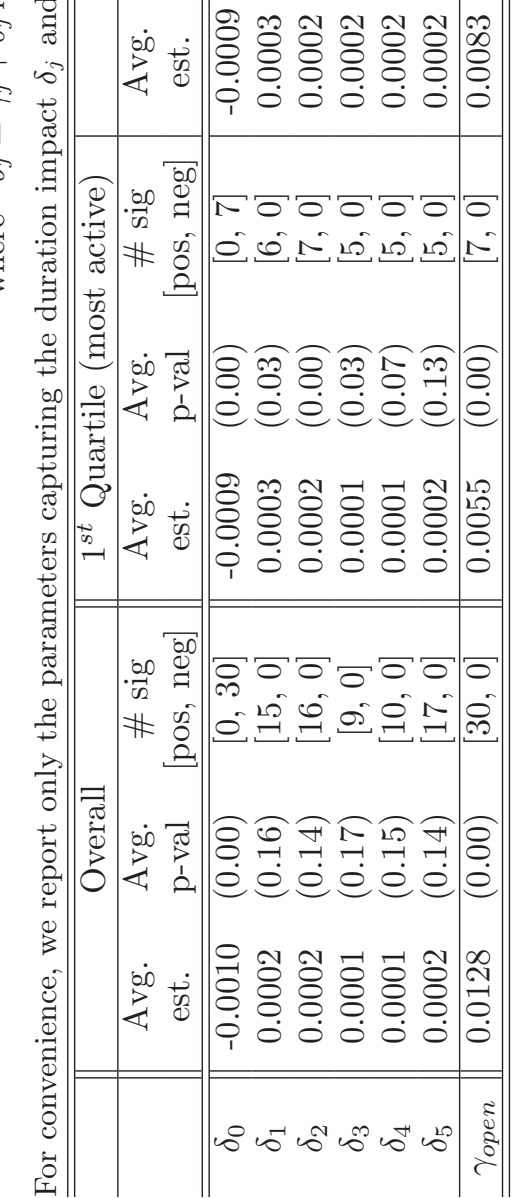




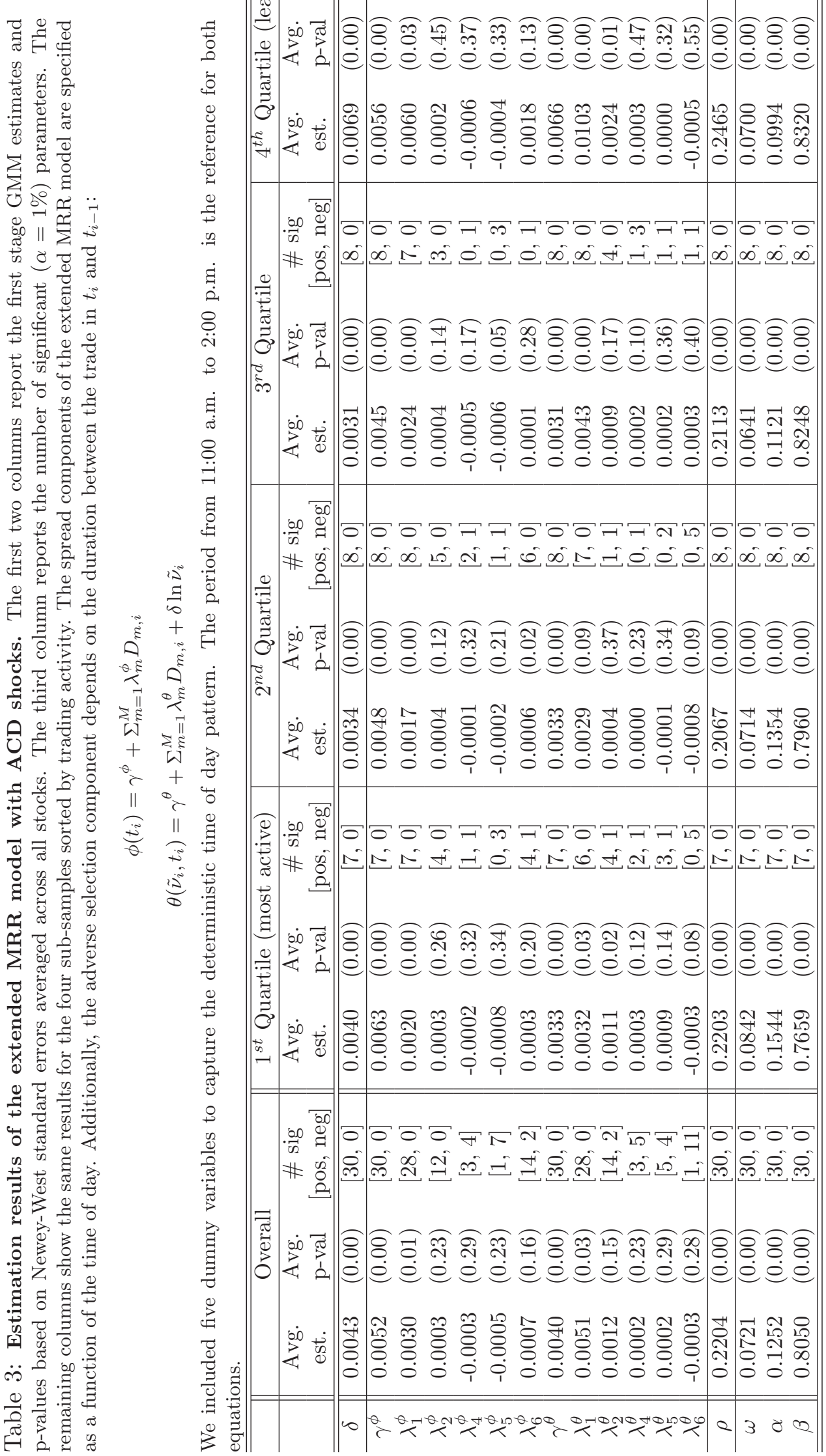


Table 4: Adverse selection in percent of the spread. The table reports several average adverse selection shares for each trade activity quartile. In the first column, $\operatorname{asr}\left(\tilde{\nu}_{i}, t_{i}\right)=\frac{\theta\left(\tilde{\nu}_{i}, t_{i}\right)}{\theta\left(\tilde{\nu}_{i}, t_{i}\right)+\phi\left(t_{i}\right)}$ denotes the average adverse selection share of the spread. Additionally, in the second column, $\operatorname{asr}\left(\tilde{\nu}_{i}\right)=\frac{\theta\left(\tilde{\nu}_{i}\right)}{\theta\left(\tilde{\nu}_{i}, t_{i}\right)+\phi\left(t_{i}\right)}$ denotes the average adverse selection share of the spread explained by trade duration. dasr denotes the average fraction of the adverse selection component which can be explained by trade duration or dasr $=\frac{\theta\left(\tilde{\nu}_{i}\right)}{\theta\left(\tilde{\nu}_{i}, t_{i}\right)}$. The three ratios are averaged over all trades for each trade activity quartile and for the whole sample. Note, that the adverse selection component $\theta\left(\tilde{\nu}_{i}, t_{i}\right)$ is the sum of the deterministic time of day component $\theta\left(t_{i}\right)$ and the duration dependent component $\theta\left(\tilde{\nu}_{i}\right)$.

\begin{tabular}{lccc}
\hline \hline Trading Activity Quartile & $a s r\left(\tilde{\nu}_{i}, t_{i}\right)$ & $a s r\left(\tilde{\nu}_{i}\right)$ & $d a s r$ \\
\hline \hline $1^{\text {st }}$ Quartile (most active) & 45.0 & 13.4 & 26.4 \\
$2^{\text {nd }}$ Quartile & 48.2 & 14.1 & 26.6 \\
$3^{\text {rd }}$ Quartile & 50.7 & 14.0 & 25.3 \\
$4^{\text {th }}$ Quartile (least active) & 63.8 & 18.0 & 26.5 \\
\hline Overall & 48.8 & 14.2 & 26.3 \\
\hline \hline
\end{tabular}


Table 5: Correlations of the estimated standardized spread components with several relative spread measures, market capitalization and the daily number of trades. The table reports the Pearson correlation coefficients of the estimated standardized spread components with several relative spread measures, market capitalization and the daily number of trades. $\tilde{\phi}\left(t_{i}\right)$ is the standardized order processing component, $\tilde{\theta}\left(\tilde{\nu}_{i}, t_{i}\right)$ is the standardized adverse selection component, $\tilde{\theta}\left(\tilde{\nu}_{i}\right)$ is the standardized adverse selection component due to duration and $\tilde{I S} S_{i}=2\left[\tilde{\theta}\left(\tilde{\nu}_{i}, t_{i}\right)+\tilde{\phi}\left(t_{i}\right)\right]$ denotes the implied spread. $\operatorname{asr}\left(\tilde{\nu}_{i}, t_{i}\right)=\frac{\theta\left(\tilde{\nu}_{i}, t_{i}\right)}{\theta\left(\tilde{\nu}_{i}, t_{i}\right)+\phi\left(t_{i}\right)}$ denotes the average adverse selection share of the spread computed for each stock. $\operatorname{asr}\left(\tilde{\nu}_{i}\right)=\frac{\theta\left(\tilde{\nu}_{i}\right)}{\theta\left(\tilde{\nu}_{i}, t_{i}\right)+\phi\left(t_{i}\right)}$ denotes the average adverse selection share of the spread explained by trade duration computed for each stock. $\quad d a s r=\frac{\theta\left(\tilde{\nu}_{i}\right)}{\theta\left(\tilde{\nu}_{i}, t_{i}\right)}$ denotes the average fraction of the adverse selection component which can be explained by trade duration. Correlations were computed across the sample of the 30 stocks constituting the DAX30. P-values for the correlation coefficients are in parentheses.

\begin{tabular}{c|ccccc}
\hline \hline Variable & $\begin{array}{c}\text { Effective } \\
\text { Spread (\%) }\end{array}$ & $\begin{array}{c}\text { Realized } \\
\text { Spread (\%) }\end{array}$ & $\begin{array}{c}\text { Price } \\
\text { Impact (\%) }\end{array}$ & $\begin{array}{c}\text { Market cap. } \\
\text { (Mill.) }\end{array}$ & $\begin{array}{c}\text { Daily nb. } \\
\text { trades }\end{array}$ \\
\hline \hline$\tilde{\phi}\left(t_{i}\right)$ & 0.763 & 0.881 & 0.373 & -0.351 & -0.153 \\
& $(0.000)$ & $(0.000)$ & $(0.043)$ & $(0.057)$ & $(0.419)$ \\
$\tilde{\theta}\left(\tilde{\nu}_{i}, t_{i}\right)$ & 0.782 & -0.144 & 0.965 & -0.802 & -0.893 \\
& $(0.000)$ & $(0.448)$ & $(0.000)$ & $(0.000)$ & $(0.000)$ \\
$\tilde{\theta}\left(\tilde{\nu}_{i}\right)$ & 0.624 & -0.320 & 0.884 & -0.786 & -0.890 \\
& $(0.000)$ & $(0.085)$ & $(0.000)$ & $(0.000)$ & $(0.000)$ \\
$\tilde{I} S_{i}$ & 0.996 & 0.505 & 0.845 & -0.730 & -0.653 \\
& $(0.000)$ & $(0.004)$ & $(0.000)$ & $(0.000)$ & $(0.000)$ \\
$\operatorname{asr}\left(\tilde{\nu}_{i}, t_{i}\right)$ & -0.044 & -0.827 & 0.410 & -0.334 & -0.565 \\
$\operatorname{asr}\left(\tilde{\nu}_{i}\right)$ & $(0.816)$ & $(0.000)$ & $(0.024)$ & $(0.071)$ & $(0.001)$ \\
& -0.286 & -0.855 & 0.152 & -0.191 & -0.367 \\
$\operatorname{dasr}$ & $(0.125)$ & $(0.000)$ & $(0.422)$ & $(0.311)$ & $(0.046)$ \\
& -0.436 & -0.486 & -0.223 & 0.072 & 0.053 \\
& $(0.016)$ & $(0.006)$ & $(0.237)$ & $(0.707)$ & $(0.782)$ \\
\hline \hline
\end{tabular}




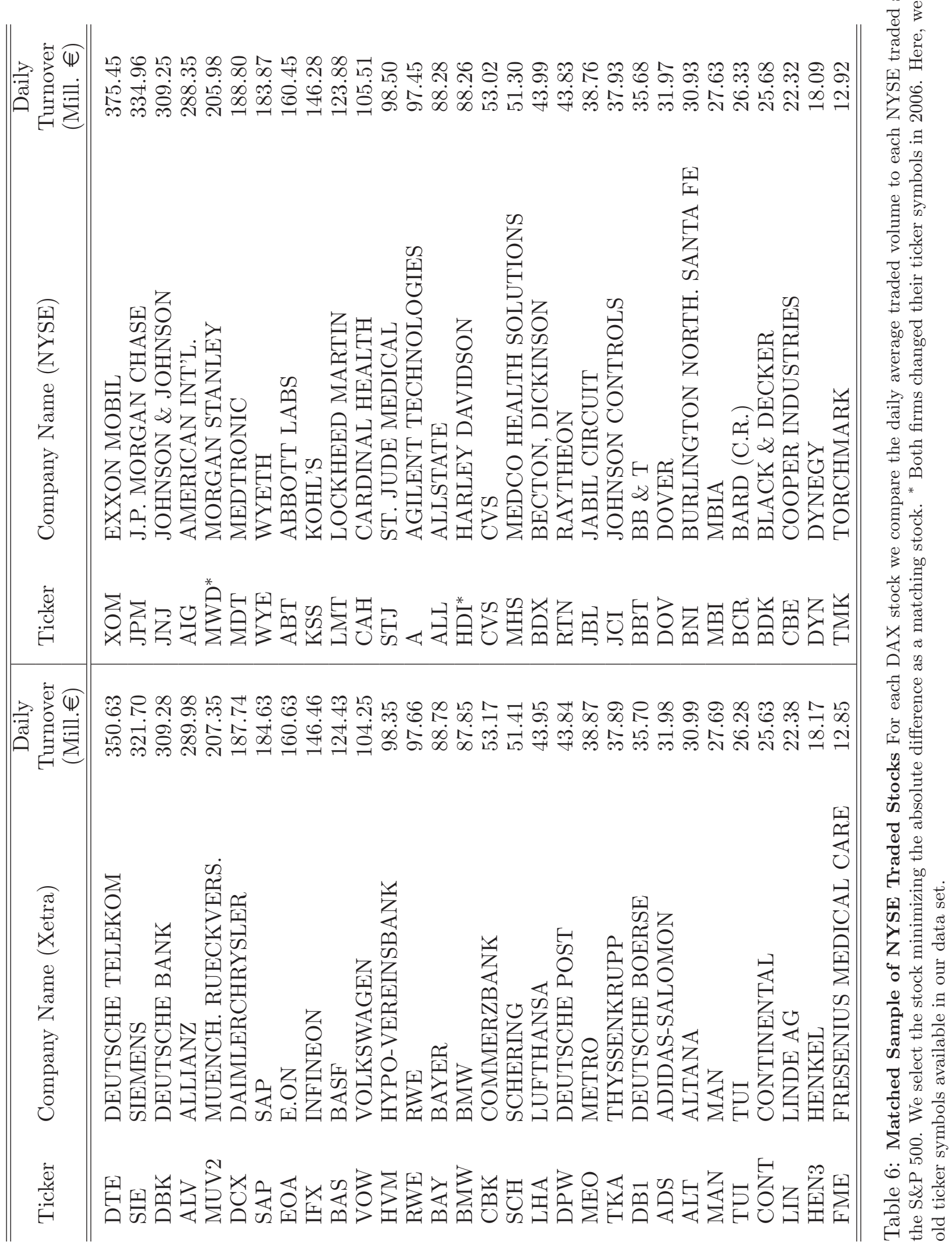


Table 7: Estimation results of the extended MRR model with ACD shocks for a matched sample of NYSE traded stocks. The first two columns report the first stage GMM estimates and p-values based on Newey-West standard errors averaged across all stocks. The third column reports the number of significant $(\alpha=1 \%)$ parameters. The spread components of the extended MRR model are specified as a function of the time of day. Additionally, the adverse selection component depends on the duration between the trade in $t_{i}$ and $t_{i-1}$ :

$$
\begin{gathered}
\phi\left(t_{i}\right)=\gamma^{\phi}+\Sigma_{m=1}^{M} \lambda_{m}^{\phi} D_{m, i} \\
\theta\left(\tilde{\nu}_{i}, t_{i}\right)=\gamma^{\theta}+\Sigma_{m=1}^{M} \lambda_{m}^{\theta} D_{m, i}+\delta \ln \tilde{\nu}_{i}
\end{gathered}
$$

We included four dummy variables to capture the deterministic time of day pattern. The period from 11:30 a.m. to 2:00 p.m. is the reference for both equations.

\begin{tabular}{c||ccc}
\hline \hline \multicolumn{1}{c||}{} & \multicolumn{3}{c}{ Overall } \\
\hline & $\begin{array}{c}\text { Avg. } \\
\text { est. }\end{array}$ & $\begin{array}{c}\text { Avg. } \\
\text { p-val }\end{array}$ & $\begin{array}{c}\text { \# sig } \\
\text { [pos, neg] }\end{array}$ \\
\hline \hline$\delta$ & 0.0009 & $(0.06)$ & {$[25,0]$} \\
\hline$\gamma^{\phi}$ & 0.0021 & $(0.00)$ & {$[30,0]$} \\
$\lambda_{1}^{\phi}$ & 0.0007 & $(0.05)$ & {$[19,0]$} \\
$\lambda_{2}^{\phi}$ & 0.0001 & $(0.20)$ & {$[13,1]$} \\
$\lambda_{4}^{\phi}$ & 0.0001 & $(0.20)$ & {$[7,2]$} \\
$\lambda_{5}^{\phi}$ & 0.0005 & $(0.09)$ & {$[19,2]$} \\
$\gamma^{\theta}$ & 0.0029 & $(0.00)$ & {$[30,0]$} \\
$\lambda_{1}^{\theta}$ & 0.0018 & $(0.03)$ & {$[25,0]$} \\
$\lambda_{2}^{\theta}$ & 0.0006 & $(0.05)$ & {$[19,1]$} \\
$\lambda_{4}^{\theta}$ & -0.0001 & $(0.31)$ & {$[2,6]$} \\
$\lambda_{5}^{\theta}$ & -0.0006 & $(0.05)$ & {$[0,24]$} \\
\hline$\rho$ & 0.2731 & $(0.00)$ & {$[30,0]$} \\
\hline$\omega$ & 0.0457 & $(0.03)$ & {$[26,0]$} \\
$\alpha$ & 0.0468 & $(0.01)$ & {$[28,0]$} \\
$\beta$ & 0.9077 & $(0.00)$ & {$[30,0]$} \\
\hline \hline
\end{tabular}




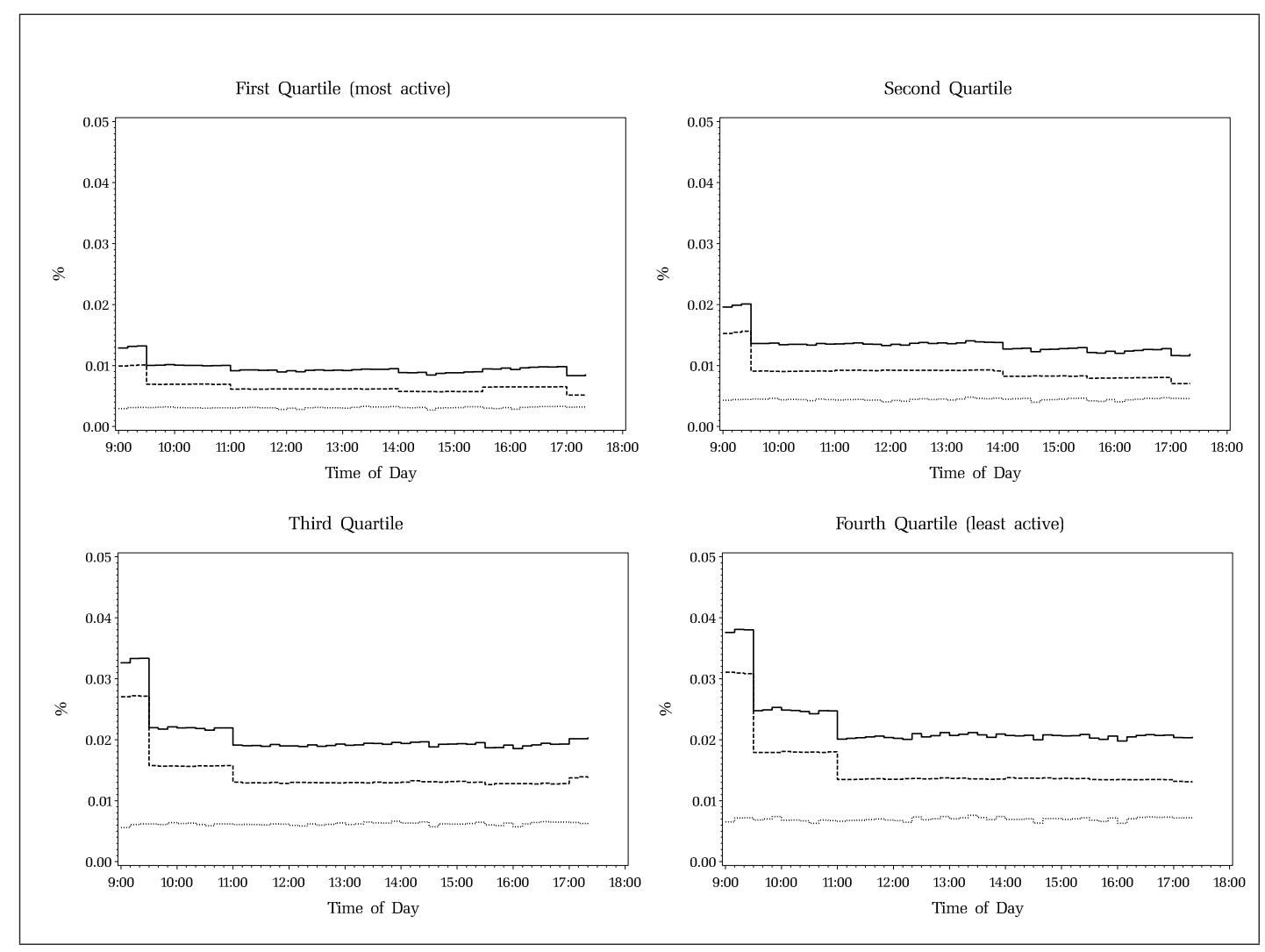

Figure 1: Intra-day patterns for the estimated standardized adverse selection components. The dotted line depicts the average standardized adverse selection component due to duration $\theta\left(\tilde{\nu}_{i}\right)$. The dashed line depicts the deterministic part of the average standardized adverse selection component $\theta\left(t_{i}\right)$. The solid line depicts the sum of $\theta\left(\tilde{\nu}_{i}\right)$ and $\theta\left(t_{i}\right)$, the complete adverse selection component $\theta\left(\tilde{\nu}_{i}, t_{i}\right)$. Top left: Intra-day patterns for the trade activity quartile 1 . Top right: Intra-day patterns for the trade activity quartile 2. Lower left: Intra-day patterns for the trade activity quartile 3. Lower right: Intra-day patterns for the trade activity quartile 4. 


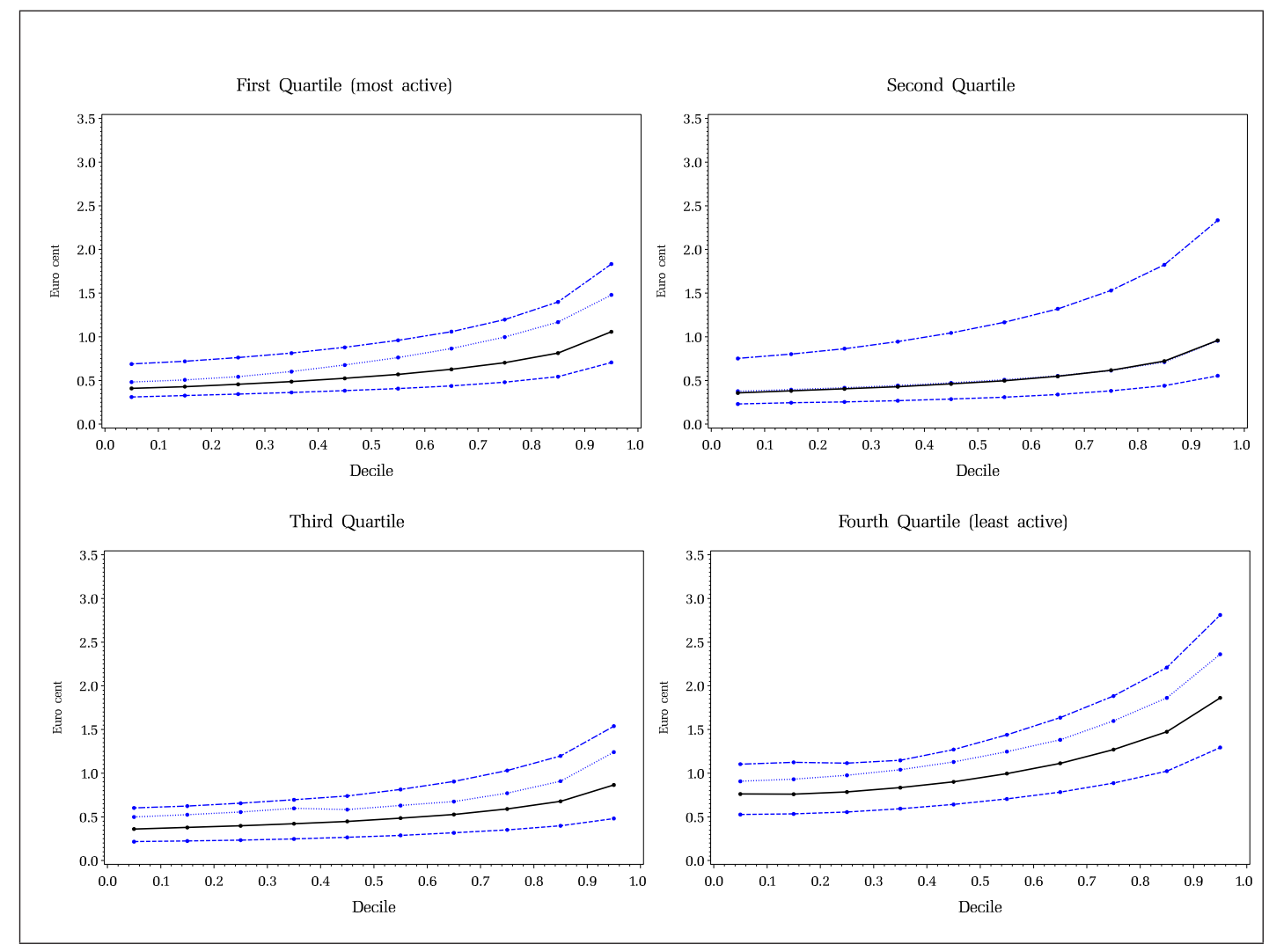

Figure 2: Time between trades versus adverse selection component. We sort (in ascending order) the trade duration shocks into deciles and compute the mean, $0.25,0.75$ and 0.9 quantile of the adverse selection component $\theta\left(\tilde{\nu}_{i}, t_{i}\right)$ in each decile and graphically display the results. The 0.25-quantiles are connected with dashed lines. The 0.75-quantiles are connected with dotted lines. The 0.9-quantiles are connected with dash-dotted lines. The decile means are connected with solid lines. All trade events of the stocks belonging to the same trading activity quartile are pooled. The top left panel displays the results for the group of most frequently trades stocks. The top right panel shows the results for the second and the lower left panel depicts the result for the third trading activity quartile. The lower right panel presents the results for the least frequently traded stocks. 


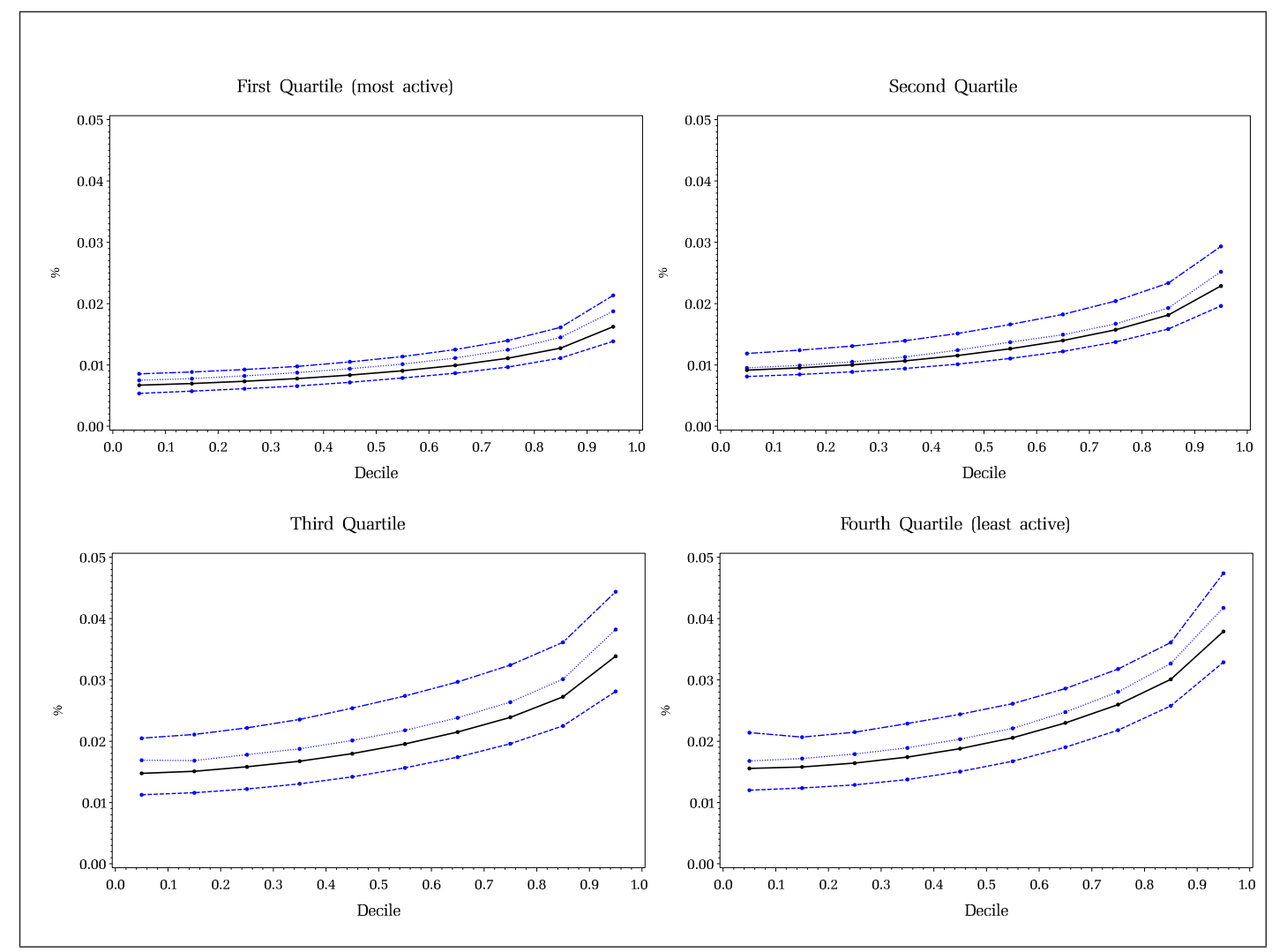

Figure 3: Time between trades versus standardized adverse selection component. We sort (in ascending order) the trade duration shocks into deciles and compute the mean, $0.25,0.75$ and 0.9 quantile of the standardized adverse selection component $\tilde{\theta}\left(\tilde{\nu}_{i}, t_{i}\right)$ in each decile and graphically display the results. The 0.25-quantiles are connected with dashed lines. The 0.75-quantiles are connected with dotted lines. The 0.9-quantiles are connected with dash-dotted lines. The decile means are connected with solid lines. All trade events of the stocks belonging to the same trading activity quartile are pooled. The top left panel displays the results for the group of most frequently trades stocks. The top right panel shows the results for the second and the lower left panel depicts the result for the third trading activity quartile. The lower right panel presents the results for the least frequently traded stocks. 
DCX

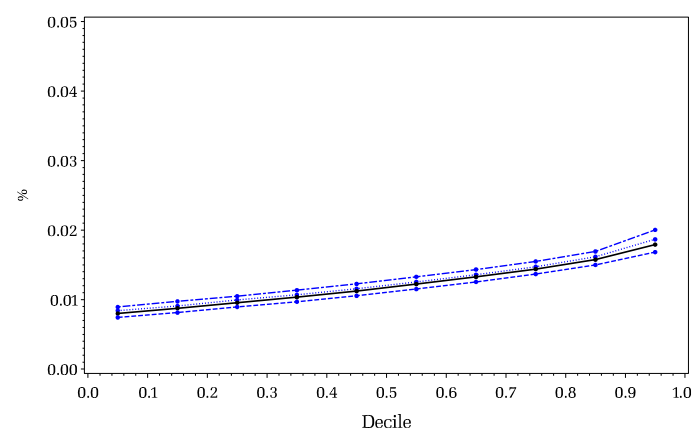

LHA

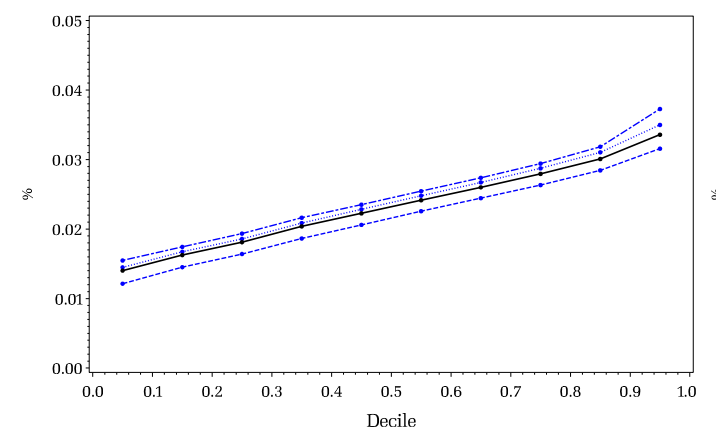

BAS

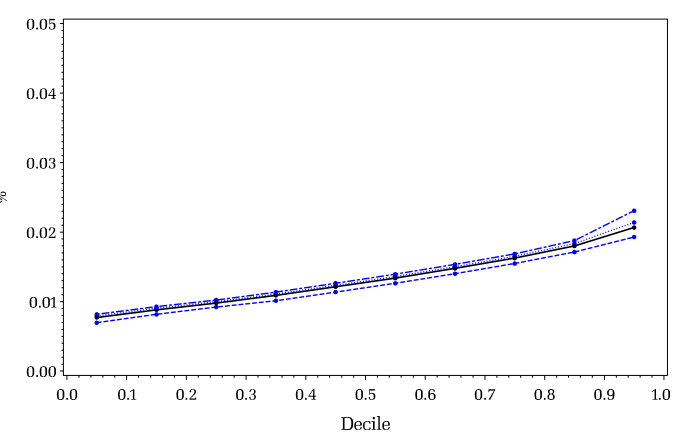

FME

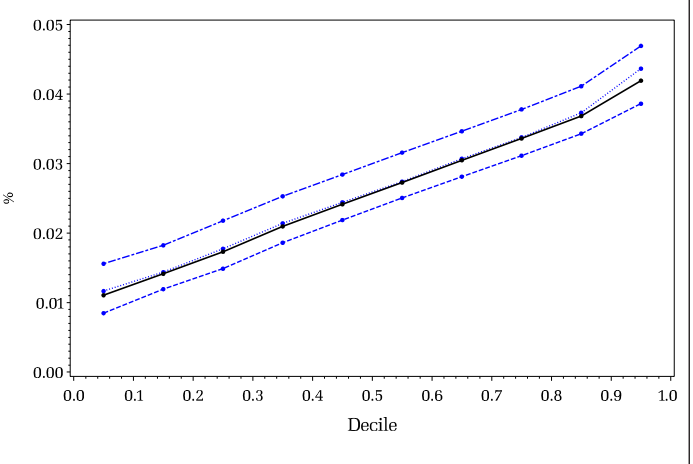

Figure 4: Time between trades versus standardized adverse selection component for individual stocks. We sort (in ascending order) the trade duration shocks into deciles and compute the mean, $0.25,0.75$ and 0.9 quantile of the adverse selection component $\theta\left(\tilde{\nu}_{i}, t_{i}\right)$ in each decile and graphically display the results. The 0.25 -quantiles are connected with dashed lines. The 0.75-quantiles are connected with dotted lines. The 0.9-quantiles are connected with dash-dotted lines. The decile means are connected with solid lines. The top left panel displays the results for a representative stock of trade activity quartile 1 . The top right panel shows the results for a representative stock of trade activity quartile 2 . The lower left panel depicts the result for a representative stock of trade activity quartile 3 and the lower right panel presents the results for a representative stock of trade activity quartile 4. All trade events of the particular stock are pooled. 


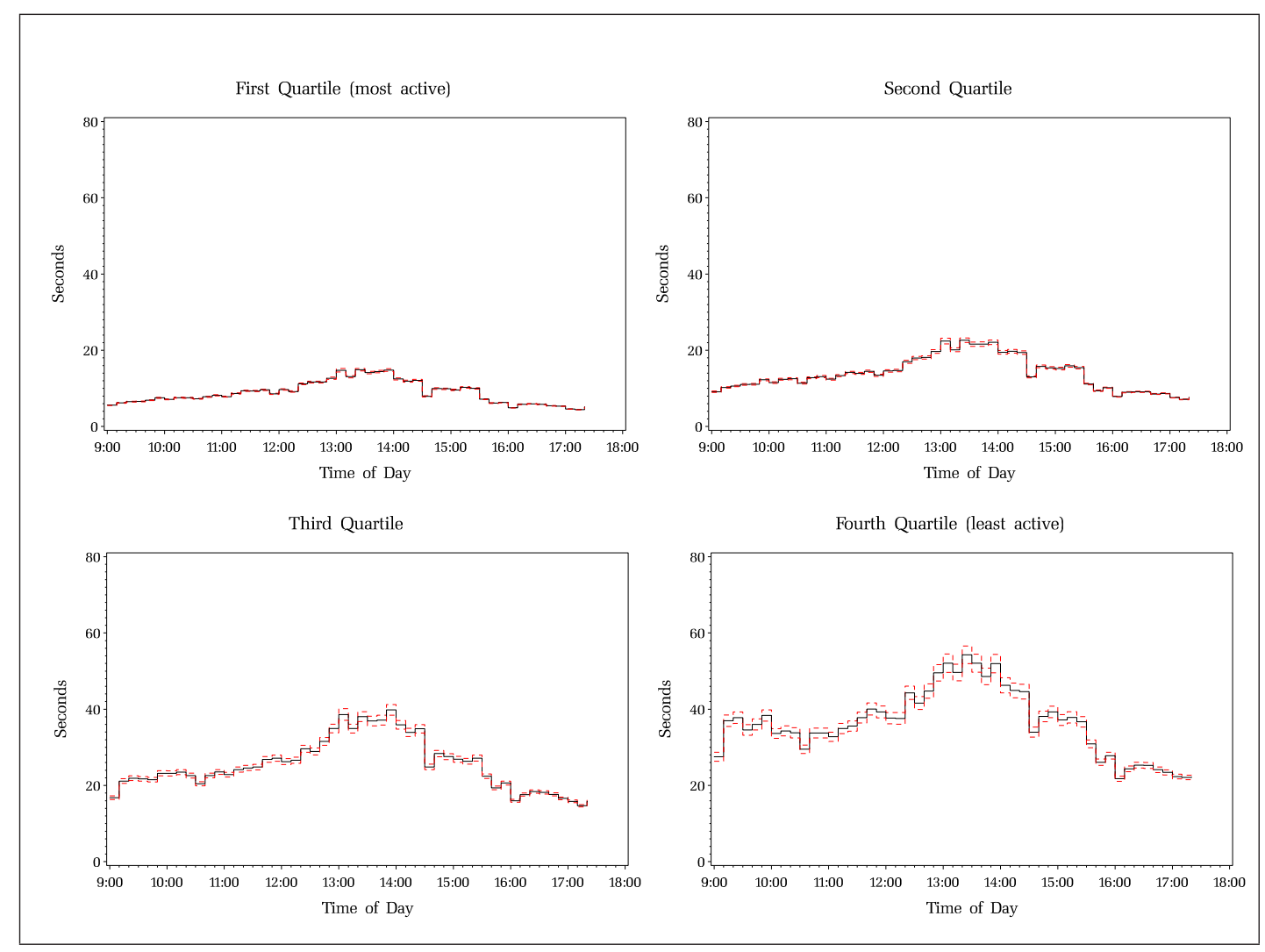

Figure 5: Intra-day pattern of trade durations. We compute for each ten minute interval of the day the average trade duration and plot the means against time of day. All trade events of the stocks belonging to the same trading activity quartile are pooled. The top left panel displays the results for the group of most frequently trades stocks. The top right panel shows the results for the second and the lower left panel depicts the result for the third trading activity quartile. The lower right panel presents the results for the least frequently traded stocks. The dashed lines are the $95 \%$ confidence intervals for the ten minute means. 


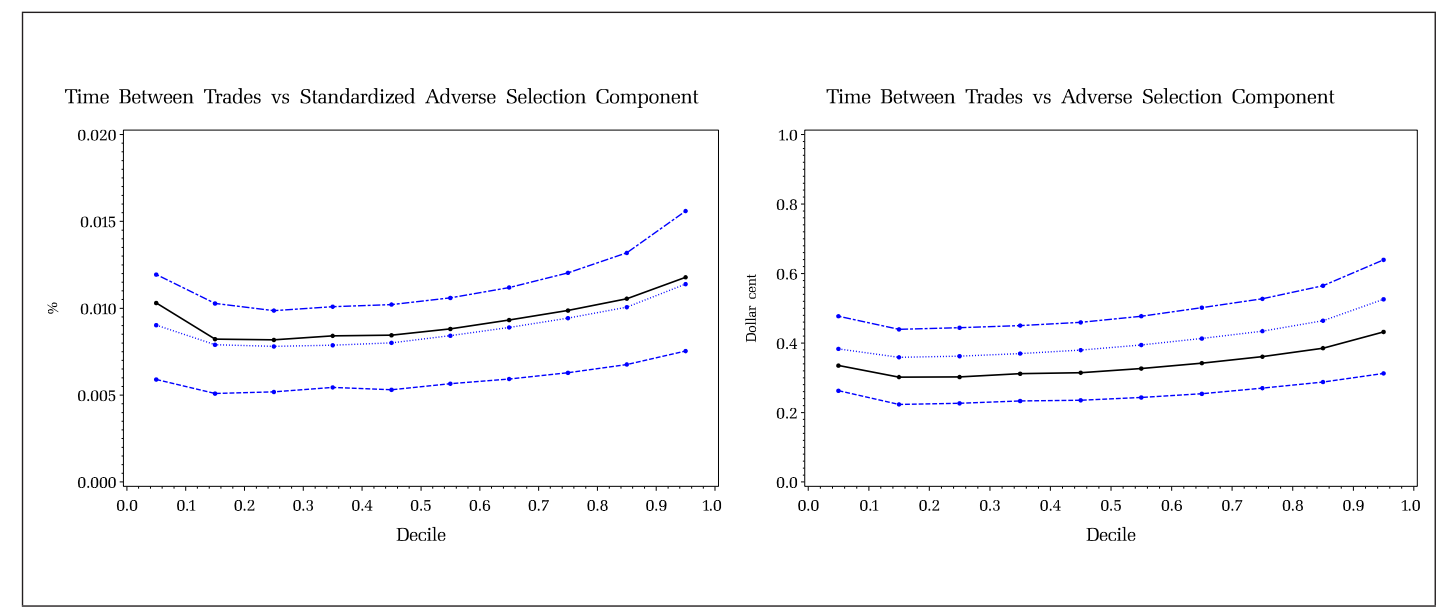

Figure 6: Results for the NYSE traded matched sample. We sort (in ascending order) the trade duration into deciles and compute the mean, $0.25,0.75$ and 0.9 quantile of the adverse selection component $\theta\left(\tilde{\nu}_{i}, t_{i}\right)$ (right panel) and the standardized adverse selection component $\tilde{\theta}\left(\tilde{\nu}_{i}, t_{i}\right)$ (left panel) in each decile and graphically display the results. The 0.25 -quantiles are connected with dashed lines. The 0.75-quantiles are connected with dotted lines. The 0.9-quantiles are connected with dash-dotted lines. The decile means are connected with solid lines. All trade events of the 30 NYSE traded stocks are pooled. 


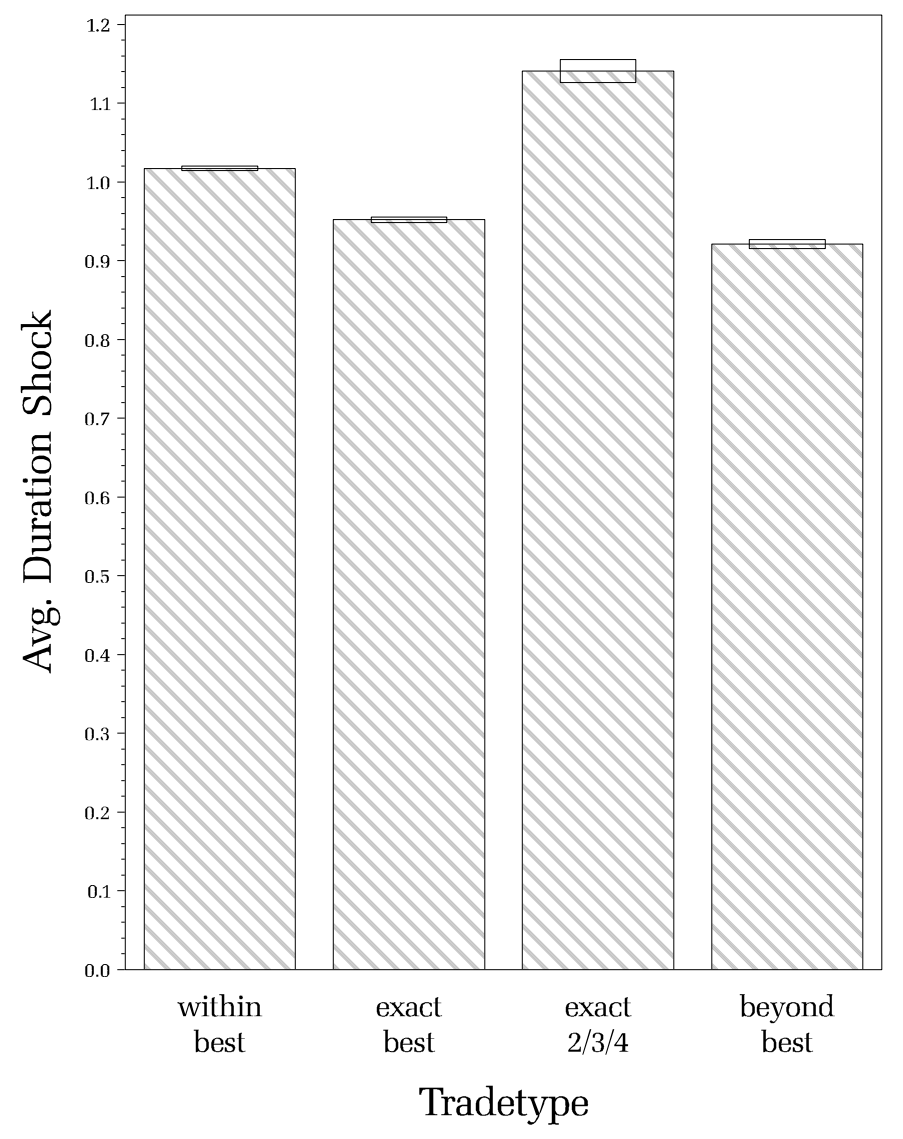

Figure 7: Average Duration Shock for Different Trade Categories. The graph depicts the average duration shock for four different trade categories. We denote with 'within best' the trades with a volume smaller than the best depth. With 'exact best' we denote the trades consuming exactly the best depth. Trades consuming exactly the depth up to the second, third or fourth best quote are categorized as 'exact $2 / 3 / 4$ ' and trades with a volume higher than the best depth but within any higher order quote are denoted as 'beyond best'. 


\section{References}

Admati, A.R., and P. Pfleiderer, 1988, A theory of intraday patterns: Volume and price variability, Review of Financial Studies 1, 3-40.

Ahn, H., K. Bae, and K. Chan, 2001, Limit orders, depth and volatility: evidence from the stock exchange of hong kong, Journal of Finance 56, 767-788.

Bauwens, L., and P. Giot, 2001, Econometric Modelling of Stock Market Intraday Activity (Kluwer Academic Publishers).

Boehmer, E., J. Grammig, and E. Theissen, 2006, Estimating the probability of informed trading - does trade misclassification matter?, Journal of Financial Markets (forthcoming).

Cao, Ch., O. Hansch, and X. Wang, 2004, The informational content of an open limit order book, EFA 2004 Working Paper, Penn State University and Southern Illinois University.

Diamond, D.W., and R.E. Verrecchia, 1987, Constraints on short-selling and asset price adjustments to private information, Journal of Financial Economics 18, 277-311.

Dufour, A., and R.F. Engle, 2000, Time and the price impact of a trade, Journal of Finance $55,2467-2498$.

Easley, D., and M. O'Hara, 1992, Time and the process of security price adjustment, Journal of Finance 47, 577-605.

Engle, Robert F., 2000, The econometrics of ultra-high frequency data, Econometrica 68, $1-22$.

Engle, R. F., and J.R. Russell, 1998, Autoregressive conditional duration: A new model for irregularly spaced transaction data, Econometrica 66, 1127-1162.

Eubank, R.L., and Paul Speckman, 1990, Curve fitting by polynomial-trigonometric regression, Biometrika 77, 1-9.

Fernandes, Marcelo, and Joachim Grammig, 2006, A family of autoregressive conditional duration models, Journal of Econometrics 130, 1-23. 
Foucault, Thierry, 1999, Order flow composition and trading costs in a dynamic limit order market, Journal of Financial Markets 2, 99-134.

Glosten, L.R., and L.E. Harris, 1988, Estimating the components of the bid-ask spread, Journal of Financial Economics 21, 123-142.

Grammig, Joachim, and Marc Wellner, 2002, Modelling the interdependence of volatility and inter-transaction duration processes, Journal of Econometrics 106, 369-400.

Harris, L., 2003, Trading and Exchanges (Oxford University Press).

Hasbrouck, J., 1991a, Measuring the information content of stock trades, Journal of Finance 46, 179-207.

Hasbrouck, Joel, 1991b, The summary informativeness of stock trades: An econometric analysis, The Review of Financial Studies 4, 571-595.

Huang, R.D., and H.R. Stoll, 1997, The components of the bid-ask spread: A general approach, Review of Financial Studies 10, 995-1034.

Lee, C. M., and M. J. Ready, 1991, Inferring trade direction from intraday data, Journal of Finance 44, 733-746.

Madhavan, A., M. Richardson, and M. Roomans, 1997, Why do security prices change? A transaction-level analysis of NYSE stocks, Review of Financial Studies 10, 1035-1064.

Parlour, Christine A., 1998, Price dynamics in limit order markets, The Review of Financial Studies 11, 789-816.

Zhang, Michael Y., Jeffrey R. Russell, and Ruey S. Tsay, 2001, A nonlinear autoregressive conditional duration model with applications to financial transaction data, Journal of Econometrics 104, 179-207. 
CFR working paper series

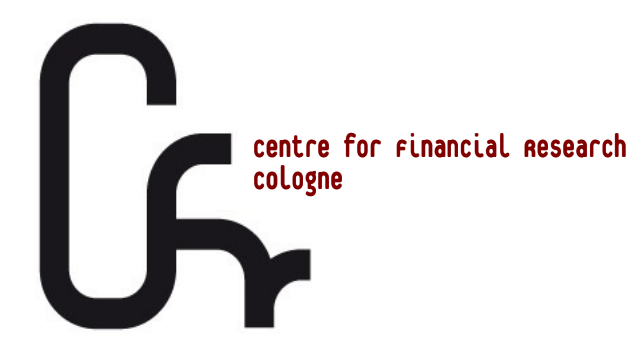

CfR working papers are available for download from www.cfr-cologne.de.

Hardcopies can be ordered from: centre for financial Research (CfR), albertus magnus platz, 50923 koeln, Germany.

2012

No. Author(s) Title

12-06 A. Kempf, A. Pütz, $\quad$ Fund Manager Duality: Impact on Performance and Investment F. Sonnenburg Behavior

12-05 R. Wermers Runs on Money Market Mutual Funds

12-04 R. Wermers A matter of style: The causes and consequences of style drift in institutional portfolios

12-03 C. Andres, A. Betzer, I. Dividend Announcements Reconsidered: van den Bongard, $C$. Dividend Changes versus Dividend Surprises Haesner, E. Theissen

12-02 C. Andres, E. Fernau, E. Is It Better To Say Goodbye? Theissen When Former Executives Set Executive Pay

12-01 L. Andreu, A. Pütz Are Two Business Degrees Better Than One? Evidence from Mutual Fund Managers' Education

2011

No. Author(s) Title

11-16 V. Agarwal, J.-P. Gómez, Management Compensation and Market Timing under Portfolio R. Priestley Constraints

11-15 T. Dimpfl, S. Jank

11-14 P. Gomber,

U. Schweickert,

E. Theissen

11-13 D. Hess, S. Orbe

11-12 D. Hess, P. Immenkötter

11-11 N. Heinrichs, D. Hess,

C. Homburg, M. Lorenz,

S. Sievers

11-10 A. Kempf, O. Korn,

S. Saßning
Can Internet Search Queries Help to Predict Stock Market Volatility?

Liquidity Dynamics in an Electronic Open Limit Order Book: An Event Study Approach

Irrationality or Efficiency of Macroeconomic Survey Forecasts? Implications from the Anchoring Bias Test

Optimal Leverage, its Benefits, and the Business Cycle

Extended Dividend, Cash Flow and Residual Income Valuation Models - Accounting for Deviations from Ideal Conditions

Portfolio Optimization using Forward - Looking Information 
$11-09$

11-07 V. Agarwal, G. D. Gay, L. Ling

11-06 N. Hautsch, D. Hess, D. Veredas

11-05 G. Cici

11-04 S. Jank

11-03 G.Fellner, E.Theissen

11-02 S.Jank

11-01 V. Agarwal, C. Meneghetti
Determinants and Implications of Fee Changes in the Hedge Fund Industry

On the Use of Options by Mutual Funds: Do They Know What They Are Doing?

Performance inconsistency in mutual funds: An investigation of window-dressing behavior

The Impact of Macroeconomic News on Quote Adjustments, Noise, and Informational Volatility

The Prevalence of the Disposition Effect in Mutual Funds' Trades

Mutual Fund Flows, Expected Returns and the Real Economy

Short Sale Constraints, Divergence of Opinion and Asset Value: Evidence from the Laboratory

Are There Disadvantaged Clienteles in Mutual Funds?

The Role of Hedge Funds as Primary Lenders

2010

No. Author(s) Title

10-20 G. Cici, S. Gibson, J.J. Merrick Jr.

10-19 J. Hengelbrock,

E. Theissen, C. Westheide

$10-18$

G. Cici, S. Gibson

10-17 D. Hess, D. Kreutzmann,

O. Pucker

$10-16$

S. Jank, M. Wedow

10-15

G. Cici, A. Kempf, A. Puetz

10-14

J. Grammig, S. Jank

10-13 S. Jank, M. Wedow

10-12 S. Artmann, P. Finter,

A. Kempf, S. Koch,

E. Theissen

10-11 M. Chesney, A. Kempf

10-10 S. Frey, P. Herbst

10-09 V. Agarwal, W. Jiang,

Y. Tang, B. Yang

10-08 V. Agarwal, V. Fos, W. Jiang

10-07
Missing the Marks? Dispersion in Corporate Bond Valuations Across Mutual Funds

Market Response to Investor Sentiment

The Performance of Corporate-Bond Mutual Funds:

Evidence Based on Security-Level Holdings

Projected Earnings Accuracy and the Profitability of Stock Recommendations

Sturm und Drang in Money Market Funds: When Money Market Funds Cease to Be Narrow

The Valuation of Hedge Funds' Equity Positions

Creative Destruction and Asset Prices

Purchase and Redemption Decisions of Mutual Fund Investors and the Role of Fund Families

The Cross-Section of German Stock Returns:

New Data and New Evidence

The Value of Tradeability

The Influence of Buy-side Analysts on Mutual Fund Trading

Uncovering Hedge Fund Skill from the Portfolio Holdings They Hide

Inferring Reporting Biases in Hedge Fund Databases from Hedge Fund Equity Holdings

Do Higher-Moment Equity Risks Explain Hedge Fund 
J. Huij Returns?

\begin{tabular}{|c|c|c|}
\hline $10-06$ & J. Grammig, F. J. Peter & Tell-Tale Tails \\
\hline $10-05$ & K. Drachter, A. Kempf & $\begin{array}{l}\text { Höhe, Struktur und Determinanten der Managervergütung- } \\
\text { Eine Analyse der Fondsbranche in Deutschland }\end{array}$ \\
\hline $10-04$ & $\begin{array}{l}\text { J. Fang, A. Kempf, } \\
\text { M. Trapp }\end{array}$ & Fund Manager Allocation \\
\hline $10-03$ & $\begin{array}{l}\text { P. Finter, A. Niessen- } \\
\text { Ruenzi, S. Ruenzi }\end{array}$ & The Impact of Investor Sentiment on the German Stock Market \\
\hline $10-02$ & $\begin{array}{l}\text { D. Hunter, E. Kandel, } \\
\text { S. Kandel, R. Wermers }\end{array}$ & Endogenous Benchmarks \\
\hline $10-01$ & $\begin{array}{l}\text { S. Artmann, P. Finter, } \\
\text { A. Kempf }\end{array}$ & $\begin{array}{l}\text { Determinants of Expected Stock Returns: Large Sample } \\
\text { Evidence from the German Market }\end{array}$ \\
\hline
\end{tabular}

2009

\begin{tabular}{|c|c|c|}
\hline No. & Author(s) & Title \\
\hline $09-17$ & E. Theissen & $\begin{array}{l}\text { Price Discovery in Spot and Futures Markets: } \\
\text { A Reconsideration }\end{array}$ \\
\hline $09-16$ & M. Trapp & $\begin{array}{l}\text { Trading the Bond-CDS Basis - The Role of Credit Risk } \\
\text { and Liquidity }\end{array}$ \\
\hline $09-15$ & $\begin{array}{l}\text { A. Betzer, J. Gider, } \\
\text { D.Metzger, E. Theissen }\end{array}$ & Strategic Trading and Trade Reporting by Corporate Insiders \\
\hline $09-14$ & $\begin{array}{l}\text { A. Kempf, O. Korn, } \\
\text { M. Uhrig-Homburg }\end{array}$ & The Term Structure of Illiquidity Premia \\
\hline $09-13$ & W. Bühler, M. Trapp & $\begin{array}{l}\text { Time-Varying Credit Risk and Liquidity Premia in Bond and } \\
\text { CDS Markets }\end{array}$ \\
\hline $09-12$ & W. Bühler, M. Trapp & $\begin{array}{l}\text { Explaining the Bond-CDS Basis - The Role of Credit Risk and } \\
\text { Liquidity }\end{array}$ \\
\hline $09-11$ & $\begin{array}{l}\text { S. J. Taylor, P. K. Yadav, } \\
\text { Y. Zhang }\end{array}$ & Cross-sectional analysis of risk-neutral skewness \\
\hline $09-10$ & $\begin{array}{l}\text { A. Kempf, C. Merkle, } \\
\text { A. Niessen-Ruenzi }\end{array}$ & $\begin{array}{l}\text { Low Risk and High Return - Affective Attitudes and Stock } \\
\text { Market Expectations }\end{array}$ \\
\hline $09-09$ & $\begin{array}{l}\text { V. Fotak, V. Raman, } \\
\text { P. K. Yadav }\end{array}$ & Naked Short Selling: The Emperor's New Clothes? \\
\hline $09-08$ & $\begin{array}{l}\text { F. Bardong, S.M. Bartram, } \\
\text { P.K. Yadav }\end{array}$ & $\begin{array}{l}\text { Informed Trading, Information Asymmetry and Pricing of } \\
\text { Information Risk: Empirical Evidence from the NYSE }\end{array}$ \\
\hline $09-07$ & $\begin{array}{l}\text { S. J. Taylor , P. K. Yadav, } \\
\text { Y. Zhang }\end{array}$ & $\begin{array}{l}\text { The information content of implied volatilities and model-free } \\
\text { volatility expectations: Evidence from options written on } \\
\text { individual stocks }\end{array}$ \\
\hline $09-06$ & S. Frey, P. Sandas & The Impact of Iceberg Orders in Limit Order Books \\
\hline $09-05$ & $\begin{array}{l}\text { H. Beltran-Lopez, P. Giot, } \\
\text { J. Grammig }\end{array}$ & Commonalities in the Order Book \\
\hline 09-04 & J. Fang, S. Ruenzi & $\begin{array}{l}\text { Rapid Trading bei deutschen Aktienfonds: } \\
\text { Evidenz aus einer großen deutschen Fondsgesellschaft }\end{array}$ \\
\hline $09-03$ & $\begin{array}{l}\text { A. Banegas, B. Gillen, } \\
\text { A. Timmermann, } \\
\text { R. Wermers }\end{array}$ & The Performance of European Equity Mutual Funds \\
\hline
\end{tabular}


09-02

09-01
J. Grammig, A. Schrimpf, M. Schuppli

O. Korn, P. Koziol
Long-Horizon Consumption Risk and the Cross-Section of Returns: New Tests and International Evidence

The Term Structure of Currency Hedge Ratios

2008

\begin{tabular}{|c|c|c|}
\hline No. & Author(s) & Title \\
\hline $08-12$ & $\begin{array}{l}\text { U. Bonenkamp, } \\
\text { C. Homburg, A. Kempf }\end{array}$ & Fundamental Information in Technical Trading Strategies \\
\hline $08-11$ & O. Korn & Risk Management with Default-risky Forwards \\
\hline $08-10$ & J. Grammig, F.J. Peter & $\begin{array}{l}\text { International Price Discovery in the Presence } \\
\text { of Market Microstructure Effects }\end{array}$ \\
\hline $08-09$ & C. M. Kuhnen, A. Niessen & Public Opinion and Executive Compensation \\
\hline $08-08$ & A. Pütz, S. Ruenzi & $\begin{array}{l}\text { Overconfidence among Professional Investors: Evidence from } \\
\text { Mutual Fund Managers }\end{array}$ \\
\hline $08-07$ & P. Osthoff & What matters to SRI investors? \\
\hline $08-06$ & A. Betzer, E. Theissen & $\begin{array}{l}\text { Sooner Or Later: Delays in Trade Reporting by Corporate } \\
\text { Insiders }\end{array}$ \\
\hline $08-05$ & P. Linge, E. Theissen & $\begin{array}{l}\text { Determinanten der Aktionärspräsenz auf } \\
\text { Hauptversammlungen deutscher Aktiengesellschaften }\end{array}$ \\
\hline $08-04$ & $\begin{array}{l}\text { N. Hautsch, D. Hess, } \\
\text { C. Müller }\end{array}$ & Price Adjustment to News with Uncertain Precision \\
\hline $08-03$ & $\begin{array}{l}\text { D. Hess, H. Huang, } \\
\text { A. Niessen }\end{array}$ & $\begin{array}{l}\text { How Do Commodity Futures Respond to Macroeconomic } \\
\text { News? }\end{array}$ \\
\hline $08-02$ & $\begin{array}{l}\text { R. Chakrabarti, } \\
\text { W. Megginson, P. Yadav }\end{array}$ & Corporate Governance in India \\
\hline $08-01$ & C. Andres, E. Theissen & $\begin{array}{l}\text { Setting a Fox to Keep the Geese - Does the Comply-or-Explain } \\
\text { Principle Work? }\end{array}$ \\
\hline
\end{tabular}

2007

No. Author(s) Title

07-16 M. Bär, A. Niessen, The Impact of Work Group Diversity on Performance:

S. Ruenzi

Large Sample Evidence from the Mutual Fund Industry

07-15 A. Niessen, S. Ruenzi

Political Connectedness and Firm Performance:

Evidence From Germany

07-14 O. Korn

Hedging Price Risk when Payment Dates are Uncertain

07-13 A. Kempf, P. Osthoff

SRI Funds: Nomen est Omen

07-12 J. Grammig, E. Theissen, Time and Price Impact of a Trade: A Structural Approach

O. Wuensche

07-11 V. Agarwal, J. R. Kale

On the Relative Performance of Multi-Strategy and Funds of Hedge Funds

07-10 M. Kasch-Haroutounian, Competition Between Exchanges: Euronext versus Xetra

E. Theissen

07-09 V. Agarwal, N. D. Daniel, Do hedge funds manage their reported returns?

N. Y. Naik 
07-08 N. C. Brown, K. D. Wei, R. Wermers

\begin{tabular}{|c|c|}
\hline 07-07 & A. Betzer, E. Theissen \\
\hline 07-06 & V. Agarwal, L. Wang \\
\hline 07-05 & J. Grammig, A. Schrimpf \\
\hline 07-04 & $\begin{array}{l}\text { V. Agarwal, N.M. Boyson, } \\
\text { N.Y. Naik }\end{array}$ \\
\hline 07-03 & D. Hess, A. Niessen \\
\hline 07-02 & $\begin{array}{l}\text { A. Kempf, S. Ruenzi, } \\
\text { T. Thiele }\end{array}$ \\
\hline 07-01 & M. Hagemeister, A. Kempf \\
\hline
\end{tabular}

Analyst Recommendations, Mutual Fund Herding, and Overreaction in Stock Prices

Insider Trading and Corporate Governance:

The Case of Germany

Transaction Costs and Value Premium

Asset Pricing with a Reference Level of Consumption: New Evidence from the Cross-Section of Stock Returns

Hedge Funds for retail investors?

An examination of hedged mutual funds

The Early News Catches the Attention:

On the Relative Price Impact of Similar Economic Indicators

Employment Risk, Compensation Incentives and Managerial Risk Taking - Evidence from the Mutual Fund Industry -

CAPM und erwartete Renditen: Eine Untersuchung auf Basis der Erwartung von Marktteilnehmern

2006

No.

Author(s)

Title

06-13 S. Čeljo-Hörhager,

How do Self-fulfilling Prophecies affect Financial Ratings? - An

A. Niessen experimental study

06-12 R. Wermers, Y. Wu,

J. Zechner

Portfolio Performance, Discount Dynamics, and the Turnover of Closed-End Fund Managers

06-11 U. v. Lilienfeld-Toal,

S. Ruenzi

06-10 A. Kempf, P. Osthoff

Why Managers Hold Shares of Their Firm: An Empirical Analysis

06-09 R. Wermers, T. Yao,

J. Zhao
06-09

The Effect of Socially Responsible Investing on Portfolio

Performance

Extracting Stock Selection Information from Mutual Fund holdings: An Efficient Aggregation Approach

06-08 M. Hoffmann, B. Kempa The Poole Analysis in the New Open Economy

Macroeconomic Framework

06-07 K. Drachter, A. Kempf, M. Wagner

Decision Processes in German Mutual Fund Companies:

Evidence from a Telephone Survey

06-06 J.P. Krahnen, F.A. Schmid, E. Theissen

Investment Performance and Market Share: A Study of the German Mutual Fund Industry

06-05 S. Ber, S. Ruenzi

On the Usability of Synthetic Measures of Mutual Fund NetFlows

06-04 A. Kempf, D. Mayston

Liquidity Commonality Beyond Best Prices

06-03 O. Korn, C. Koziol

Bond Portfolio Optimization: A Risk-Return Approach

06-02 O. Scaillet, L. Barras, R. Wermers

False Discoveries in Mutual Fund Performance: Measuring Luck in Estimated Alphas

06-01 A. Niessen, S. Ruenzi

Sex Matters: Gender Differences in a Professional Setting

No.

Author(s)

Title

05-16

E. Theissen

An Analysis of Private Investors' Stock Market Return Forecasts 

E. Theissen

05-14

R. Kosowski,

A. Timmermann,

R. Wermers, H. White

05-13 D. Avramov, R. Wermers

05-12 K. Griese, A. Kempf

05-11 S. Ber, A. Kempf,

S. Ruenzi

05-10 M. Bär, A. Kempf,

S. Ruenzi

05-09 M. Hoffmann

05-08 S. Ruenzi

05-07 A. Kempf, S. Ruenzi

05-06 J. Grammig, E. Theissen

05-05 H. Beltran-Lopez, J. Grammig, A.J. Menkveld

05-04 M. Hoffmann

05-03 M. Hoffmann

05-02 A. Kempf, C. Memmel

05-01 S. Frey, J. Grammig
Does Anonymity Matter in Electronic Limit Order Markets

Can Mutual Fund „Stars" Really Pick Stocks?

New Evidence from a Bootstrap Analysis

Investing in Mutual Funds when Returns are Predictable

Liquiditätsdynamik am deutschen Aktienmarkt

Determinanten der Mittelzuflüsse bei deutschen Aktienfonds

Is a Team Different From the Sum of Its Parts?

Evidence from Mutual Fund Managers

Saving, Investment and the Net Foreign Asset Position

Mutual Fund Growth in Standard and Specialist Market Segments

Status Quo Bias and the Number of Alternatives - An Empirical Illustration from the Mutual Fund Industry

Is Best Really Better? Internalization of Orders in an Open Limit Order Book

Limit order books and trade informativeness

Compensating Wages under different Exchange rate Regimes

Fixed versus Flexible Exchange Rates: Evidence from Developing Countries

Estimating the Global Minimum Variance Portfolio

Liquidity supply and adverse selection in a pure limit order book market

2004

No.

Author(s)

Title

04-10 N. Hautsch, D. Hess

Bayesian Learning in Financial Markets - Testing for the Relevance of Information Precision in Price Discovery

04-09 A. Kempf, K. Kreuzberg

Portfolio Disclosure, Portfolio Selection and Mutual Fund Performance Evaluation

04-08 N.F. Carline, S.C. Linn, P.K. Yadav

Operating performance changes associated with corporate mergers and the role of corporate governance

04-07 J.J. Merrick, Jr., N.Y. Naik, Strategic Trading Behaviour and Price Distortion in a P.K. Yadav

Manipulated Market: Anatomy of a Squeeze

04-06 N.Y. Naik, P.K. Yadav

Trading Costs of Public Investors with Obligatory and Voluntary Market-Making: Evidence from Market Reforms

04-05 A. Kempf, S. Ruenzi

Family Matters: Rankings Within Fund Families and Fund Inflows

04-04 V. Agarwal, N.D. Daniel, N.Y. Naik

Role of Managerial Incentives and Discretion in Hedge Fund Performance

04-03 V. Agarwal, W.H. Fung, J.C. Loon, N.Y. Naik

Risk and Return in Convertible Arbitrage:

Evidence from the Convertible Bond Market

04-02 A. Kempf, S. Ruenzi

Tournaments in Mutual Fund Families 
04-01

I. Chowdhury, M.

Hoffmann, A. Schabert
Inflation Dynamics and the Cost Channel of Monetary Transmission 
